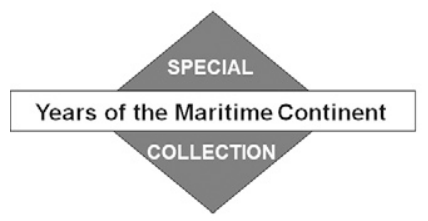

\title{
The Role of the Background Meridional Moisture Gradient on the Propagation of the MJO over the Maritime Continent ${ }^{\mathscr{O}}$
}

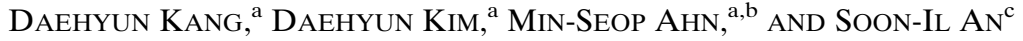 \\ ${ }^{a}$ Department of Atmospheric Sciences, University of Washington, Seattle, Washington \\ ${ }^{\mathrm{b}}$ Department of Oceanography, Chonnam National University, Gwangju, South Korea \\ ${ }^{\mathrm{c}}$ Department of Atmospheric Sciences, Yonsei University, Seoul, South Korea
}

(Manuscript received 10 February 2020, in final form 13 April 2021)

\begin{abstract}
This study investigates the role of the background meridional moisture gradient (MMG) on the propagation of the Madden-Julian oscillation (MJO) across the Maritime Continent (MC) region. It is found that the interannual variability of the seasonal mean MMG over the southern MC area is associated with the meridional expansion and contraction of the moist area in the vicinity of the MC. Sea surface temperature anomalies associated with relatively high and low seasonal mean MMG exhibit patterns that resemble those of El Niño-Southern Oscillation. By contrasting the years with anomalously low and high MMG, we show that MJO propagation through the MC is enhanced (suppressed) in years with higher (lower) seasonal mean MMG, although the effect is less robust when MMG anomalies are weak. Column-integrated moisture budget analysis further shows that sufficiently large MMG anomalies affect MJO activity by modulating the meridional advection of the mean moisture via MJO wind anomalies. Our results suggest that the background moisture distribution has a strong control over the propagation characteristics of the MJO in the $\mathrm{MC}$ region.
\end{abstract}

KEYWORDS: Madden-Julian oscillation; Intraseasonal variability; Tropical variability; Maritime Continent

\section{Introduction}

The Madden-Julian oscillation (MJO; Madden and Julian 1971, 1972) is a planetary-scale disturbance in the tropical atmosphere that propagates eastward with intraseasonal time scales of 30-90 days. As the dominant mode of tropical intraseasonal variability, the MJO affects global weather and climate (e.g., Zhang et al. 2013). The anomalously enhanced or suppressed convection associated with the MJO is tightly coupled to circulation anomalies in the tropics, through which the MJO has a large impact on a wide variety of weather and climate phenomena across different spatial and temporal scales. Some examples include the formation of tropical cyclones (Liebmann et al. 1994; Maloney and Hartmann 2000a,b; Bessafi and Wheeler 2006; Camargo et al. 2009; Klotzbach and Oliver 2015), the onset and break of the Indian

Supplemental information related to this paper is available at the Journals Online website: https://doi.org/10.1175/JCLI-D-20-0085.s1.

Kang's current affiliation: Chonnam National University, Gwangju, South Korea.

Ahn's current affiliation: Lawrence Livermore National Laboratory, Livermore, California.

Corresponding author: Daehyun Kim, daehyun@uw.edu and Australian summer monsoons (Yasunari 1979; Wheeler and McBride 2005), and the onset of some El Niño events (Takayabu et al. 1999; Kessler 2001). MJO-associated circulation anomalies also influence the mid- to high latitudes through atmospheric teleconnections (Matthews 2004; Seo and Son 2012; Dole et al. 2013; Adames and Wallace 2014). The mid- to high-latitude fingerprints of the MJO include extreme precipitation events over the western United States (Jones 2000; Bond and Vecchi 2003), the North Pacific winter storm track (Lee and Lim 2012), the North Atlantic Oscillation (Cassou 2008; Lin et al. 2009), and Arctic sea ice variability (Henderson et al. 2014).

The MJO exhibits considerable year-to-year variability (Hendon et al. 1999), which has practical implications for subseasonal-to-seasonal Earth system prediction, given that the MJO has a wide influence on the phenomena at those time scales. The seasonal tropical cyclone activity over the Atlantic, for example, is affected by how strong and how frequent the $\mathrm{MJO}$ is over the basin during the target season. Also, because the MJO influences the onset of some El Niño events (Takayabu et al. 1999; Kessler 2001), an accurate prediction of seasonal MJO activity may improve the prediction of El Niño evolution.

Most previous studies that attempted to understand the interannual variability of the MJO focused on the influence of the El Niño-Southern Oscillation (ENSO) phenomenon, which is the dominant interannual variability of the tropical 
climate system (Gualdi et al. 1999; Hendon et al. 1999; Slingo et al. 1999; Waliser et al. 2002; Pohl and Matthews 2007; Tang and Yu 2008; Gushchina and Dewitte 2012; Wilson et al. 2013; Juan Feng et al. 2015).

Earlier studies concluded that ENSO had a small impact on global MJO activity, based on the weak linear correlation between seasonal MJO activity and Niño indices (Hendon et al. 1999; Slingo et al. 1999). However, more recent studies have shown that ENSO influences the regional characteristics of MJO propagation and amplitude (Kessler 2001; Roundy and Kiladis 2006; Pohl and Matthews 2007; Roundy and Kravitz 2009; Gushchina and Dewitte 2012; Juan Feng et al. 2015). During the warm phase of ENSO_El Niño events - the MJO tends to propagate farther east over the Pacific (Kessler 2001), and its phase speed increases ${ }^{1}$ over the Maritime Continent (MC) (Pohl and Matthews 2007; Wei and Ren 2019), while the dry condition over the MC area could inhibit MJO propagation (Hendon et al. 2007).

More recently, it has been shown that central Pacific (CP) El Niño events (Ashok et al. 2007; Kao and Yu 2009; Kug et al. 2009) affect MJO activity differently than eastern Pacific (EP) El Niño events (Gushchina and Dewitte 2012; Chen et al. 2016; Hsu and Xiao 2017; Wei and Ren 2019; Juan Feng et al. 2015). For example, seasonal $\mathrm{MJO}$ activity during the mature and decaying phase of $\mathrm{CP} \mathrm{El}$ Niño events is stronger than that during EP El Niño events (Chen et al. 2016; Hsu and Xiao 2017; Wang et al. 2018; Wei and Ren 2019). The mechanisms explaining the different MJO activity between the two types of El Niño events, however, remain elusive. For instance, Hsu and Xiao (2017) emphasized the role of enhanced horizontal moisture advection during the CP El Niño events in the western Indian Ocean, while Wang et al. (2018) highlighted moisture advection in the equatorial MC. Juan Feng et al. (2015) and Chen et al. (2016) suggested the suppressed condition associated with descending motion in the western Pacific (WP) during EP El Niño events as a key mechanism.

A few studies have also investigated how the Indian Ocean dipole (IOD) mode affects the MJO (Wilson et al. 2013; Benedict et al. 2015), showing that the MJO tends to be weaker during positive IOD events (Wilson et al. 2013). Zhang and Han (2020) recently studied the relationship between MJO propagation characteristics and a mode of variability-the warm pool dipole mode - that features a dipole of SST anomalies in the southeast Indian Ocean (IO) and in the central Pacific Ocean. They found that the MJO is more frequently disrupted when the southeast IO is warmer, and the central Pacific Ocean is cooler. Several recent studies reported a notable relationship of seasonal MJO activity with the quasi-biennial oscillation (QBO; Son et al. 2017; Yoo and Son 2016; Zhang and Zhang 2018; Nishimoto and Yoden 2017; Hendon and Abhik 2018). It has been shown that MJO activity around the MC during is stronger during an easterly phase QBO winter than that of a westerly phase QBO. Despite the robust statistical relationship, however, the mechanism behind the QBO-MJO relationship has

\footnotetext{
${ }^{1}$ Note that Tam and Lau (2005) argued the opposite-that the phase speed of the MJO decreases during the warm phase of the ENSO—based on their GCM results.
}

remained elusive and the global climate models (GCMs) are unable to reproduce the observed association of the MJO with the QBO phase (e.g., Lee and Klingaman 2018; H. Kim et al. 2020).

Despite the recent progress in documenting changes in $\mathrm{MJO}$ characteristics at the interannual time scale, progress in understanding those changes appears to be slow, leaving the following questions unanswered: How do slowly varying background states such as large-scale sea surface temperature (SST) anomalies affect the propagation and maintenance of the MJO? The lack of satisfactory answers to this question reflects that our understanding of the interannual variation of the MJO is limited. The lack of a consensus on the mechanism involved in the interannual variation of the MJO is partly due to the fact that our understanding of the MJO has remained incomplete, and there are diverse views on the dynamics of the phenomenon (Zhang et al. 2013, 2020; Jiang et al. 2020). Readers are referred to Zhang et al. (2020) and Jiang et al. (2020) for recent reviews of and comparisons between existing MJO theories.

Among the existing theories is the moisture mode theory, which is based on the idea that the maintenance and propagation of the MJO can be explained by those of moisture anomalies (e.g., Raymond 2001; Sobel et al. 2001). Since the early 2000s, the idea of considering the MJO as a moisture mode has gained considerable attention [see Adames et al. (2020) for a review on the development of moisture mode theories for the MJO], which has led to the development of moisture mode models of the MJO (Sobel and Maloney 2012, 2013; Adames and Kim 2016; Fuchs and Raymond 2017). Previous studies that employed the moisture mode framework have examined the moist static energy (MSE) or moisture budget of the MJO in observations and model simulations, and have found that horizontal advection of the mean moisture by MJO perturbation winds plays an important role in the propagation of the MJO (Kiranmayi and Maloney 2011; Andersen and Kuang 2012; Kim et al. 2014; Wang et al. 2017; Ren et al. 2021, among many others). However, the moisture mode framework has not been fully utilized to understand the impact of interannual variability on MJO activity.

Many recent studies based on the moisture mode view of the MJO have pinpointed the mean state moisture, especially its horizontal gradient, as a key factor that affects the propagation of the MJO (e.g., Gonzalez and Jiang 2017; Jiang 2017; DeMott et al. 2019; Ahn et al. 2020b; Kang et al. 2020). Gonzalez and Jiang (2017) and Ahn et al. (2020b) showed that models with a more realistic mean state moisture pattern have better MJO simulation in two different model groups. A similar effect of the mean state meridional moisture gradient was revealed even in an ensemble simulation made with a single model, suggesting its independent role from that of model parameterizations (Kang et al. 2020). DeMott et al. (2019) demonstrated that the systematic improvement of MJO simulation fidelity in the ocean-atmosphere coupled GCMs over their uncoupled counterparts can be attributed to the sharper mean state moisture gradient in the coupled models. In the above-mentioned studies, it was found that, with a more realistic mean state, relatively good MJO models tend to simulate horizontal advection of column-integrated MSE more 
realistically, and thereby better simulate the MJO's eastward propagation. Inspired by the recent findings that suggest the critical role of mean state moisture on MJO propagation, in this study we investigate its role in the year-to-year variability of the MJO.

This manuscript is organized as follows. Section 2 describes the data and methodology employed in our study. In section 3, we first define an index that represents the meridional gradient of the background moisture in the southern MC (SMC) region during boreal winter. We then examine the large-scale SST and precipitable water (PW) anomalies associated with the background meridional moisture gradient (MMG) index. Using the index, the MJO propagation processes, including the columnintegrated moisture budget of the MJO, are analyzed in years with a relatively high and low background MMG, and the results are compared with each other. The summary and conclusions are presented in section 4.

\section{Data and method}

\section{a. Dataset}

We use the National Oceanic and Atmospheric Administration (NOAA) daily interpolated outgoing longwave radiation (OLR) product (Liebmann and Smith 1996) as a proxy for tropical convection. Various atmospheric state variables are obtained from the fifth generation of the European Centre for Medium-Range Weather Forecasts (ECMWF) reanalysis (ERA5) product (Hersbach et al. 2019). The OLR and ERA5 data are obtained for the period 1979-2018 and interpolated onto a $2.5^{\circ}$ longitude $\times 2.5^{\circ}$ latitude horizontal grid. The atmospheric field variables that are used in the columnintegrated moisture budget analysis are obtained at 27 vertical levels between the surface and $100 \mathrm{hPa}$. Daily averaged precipitation from the Tropical Rainfall Measuring Mission 3B42 version 7 (TRMM 3B42v7; Huffman et al. 2007) product is used for examining the relationship between moisture and precipitation. A gridded SST product from the Hadley Centre Sea Ice and Sea Surface Temperature dataset (HadISST; Rayner 2003) is used to examine the spatial distribution of SST anomalies associated with the mean state moisture gradient. Note that this study focuses on the year-to-year variability of MJO activity in boreal winter (December-April), the season in which MJO variance peaks (e.g., Kiladis et al. 2014).

\section{b. Examining the MJO's propagation}

We primarily focus on the propagation of the MJO across the MC from the IO, where a majority of MJO events initiate (e.g., Zhang and Ling 2017). Anomalies of OLR and moisture budget terms that are associated with the MJO are examined by analyzing lead-lag regression coefficients of 20-100-day bandpass-filtered anomalies against an IO reference time series, which is obtained by area-averaging bandpass-filtered OLR anomalies over an area located in the central IO $\left(75^{\circ}\right.$ $85^{\circ} \mathrm{E}, 5^{\circ} \mathrm{S}-5^{\circ} \mathrm{N}$; the red box in Fig. 1b). We flip the sign of the regression coefficients when presenting them in figures, so that the anomalies correspond to an enhanced convection over the equatorial IO.

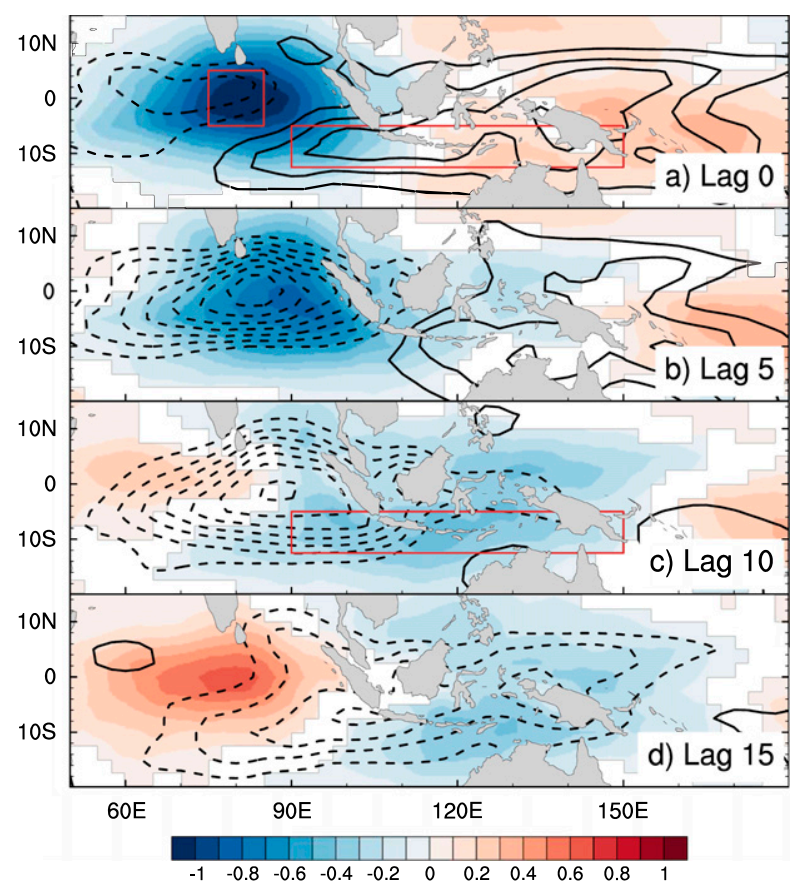

FIG. 1. The 20-100-day bandpass-filtered anomalies of OLR ( $\mathrm{W} \mathrm{m}^{-2}$; shaded) and column-integrated moisture tendency ( $\mathrm{kg} \mathrm{m}^{-2}$; contour) regressed onto the reference OLR time series from the IO base point $\left(5^{\circ} \mathrm{S}-5^{\circ} \mathrm{N}, 75^{\circ}-85^{\circ} \mathrm{E}\right)$. The column-integrated moisture tendency anomalies are weighted by $1 /\left[\overline{\tau_{c}}\right]$.

\section{c. MJO moisture budget weighted by the convective moisture adjustment timescale}

To understand MJO propagation under the moisture mode framework, a moisture budget analysis is conducted. We adopt the method of Adames (2017), who weighted the moisture budget by the "convective moisture adjustment timescale" to account for the geographical variation in the moisture-precipitation relationship. Note that while the same budget is referred to as the "precipitation budget" in Adames (2017), we use the term "moisture budget" because, for the most part, it analyzes the moisture budget of the MJO.

The mass-weighted, vertically integrated moisture budget equation takes the following form:

$$
\begin{aligned}
\frac{\partial\langle q\rangle^{\prime}}{\partial t} & =-\left\langle u \frac{\partial q}{\partial x}\right\rangle^{\prime}-\left\langle v \frac{\partial q}{\partial y}\right\rangle^{\prime}+E^{\prime}+C^{\prime} ; \\
C^{\prime} & =-\left\langle\omega \frac{\partial q}{\partial p}\right\rangle^{\prime}-P^{\prime},
\end{aligned}
$$

where $q$ is specific humidity, and $u, v$, and $\omega$ are the zonal, meridional, and vertical pressure velocities, respectively; $P$ and $E$ are precipitation and evaporation (i.e., surface latent heat flux from ERA5), respectively. The angle brackets indicate a mass-weighted vertical integral from the surface to $100 \mathrm{hPa}$, and the prime symbol denotes intraseasonal (20-100 days) anomalies. The term $C$ denotes the "column process," which consists of the vertical advection of moisture and precipitation. The column process term is 
obtained as a residual by subtracting the horizontal advection and surface evaporation terms from total moisture tendency. Note that the original definition of column process in Chikira (2014) involves evaporation, while we separately show evaporation to examine the possible effect of wind-evaporation feedback.

It is hypothesized that, over the tropical ocean, precipitation and moisture exhibit a nonlinear relationship (e.g., Bretherton et al. 2004; Rushley et al. 2018), which can be approximated in the following form:

$$
P\left(R_{h}\right)=P_{0} \exp \left(a R_{h}\right)
$$

where $R_{h}=\langle q\rangle /\left\langle q_{s}\right\rangle$ is column relative humidity (CRH) and $q_{s}$ is saturation specific humidity. The terms $P_{0}$ and $a$ are constants, and $a$ corresponds to the sensitivity parameter of precipitation with respect to $R_{h}$. Following Adames (2017), we first derive a nonlinear least squares fit from the $\mathrm{CRH}$ and precipitation data from an equatorial IO box (a $5^{\circ}$ box centered at $0^{\circ}, 95^{\circ} \mathrm{E}$ ). We obtain $P_{0}$ of $10^{-3} \mathrm{~mm} \mathrm{day}^{-1}$, and $a$ of 11.7 during boreal winter [December-April (DJFMA)] for the period 1998-2018, which is comparable to the values $\left(9.4 \times 10^{-4} \mathrm{~mm} \mathrm{day}^{-1}\right.$ and 12.1) obtained by Adames (2017). By linearizing Eq. (2) at the reference $\mathrm{CRH}$ value, which corresponds to the mean precipitation, we obtain an equation that links anomalous moisture to anomalous precipitation:

$$
P^{\prime} \cong \frac{\langle q\rangle^{\prime}}{\overline{\tau_{c}}} ; \quad \overline{\tau_{c}}=\frac{\left\langle\overline{q_{s}}\right\rangle}{a \bar{P}}
$$

where $\tau_{c}$ is the convective moisture adjustment time scale, and the overbar represents a low-frequency (100-day low-passfiltered) component. The term $\left[\overline{\tau_{c}}\right]$, the climatological mean of $\overline{\tau_{c}}$, is obtained by averaging the low-pass-filtered $\overline{\tau_{c}}$ for DJFMA 1998-2018. Note that $1 /\left[\bar{\tau}_{c}\right]$ is essentially a function of $\bar{P}$ because $\overline{q_{s}}$ varies little in the tropics and tends to be high where the mean precipitation is high (Fig. S1 in the online supplemental material). A higher value of $1 /\left[\overline{\tau_{c}}\right]$ indicates more efficient conversion of moisture anomaly to precipitation anomaly. Despite the limitations that Eq. (3) only considers moisture anomalies to estimate and does not account for other factors such as temperature perturbations, the estimated precipitation anomalies based on Eq. (3) explains about $60 \%(r=0.78)$ of precipitation variance at the intraseasonal time scale over the Indo-Pacific warm pool $\left(60^{\circ}-180^{\circ} \mathrm{E}\right.$, $\left.15^{\circ} \mathrm{S}-15^{\circ} \mathrm{N}\right)$.

Using Eq. (3), Eq. (1a) can be rewritten as follows:

$$
\frac{\partial P^{\prime}}{\partial t}=-\frac{1}{\left[\overline{\tau_{c}}\right]}\left\langle u \frac{\partial q}{\partial x}\right\rangle^{\prime}-\frac{1}{\left[\overline{\tau_{c}}\right]}\left\langle v \frac{\partial q}{\partial y}\right\rangle^{\prime}+\frac{E^{\prime}}{\left[\overline{\tau_{c}}\right]}+\frac{C^{\prime}}{\left[\overline{\bar{\tau}_{c}}\right]} \text {. }
$$

Equation (4) is more directly related to anomalous precipitation, hence the diabatic heating, associated with the MJO than Eq. (1a). Hereafter, when presenting and discussing moisture budget terms, we refer to those that are weighted by $1 /\left[\bar{\tau}_{c}\right]$ [i.e., those in Eq. (4)] unless otherwise mentioned.

\section{d. Time scale decomposition of moisture budget terms}

The horizontal moisture advection terms in Eq. (4) can be decomposed to examine the relative roles of the mean state and MJO-scale anomalies. The moisture and velocity fields are decomposed into the low-frequency background (>100 days), intraseasonal (20-100 days), and high-frequency ( $<20$ days) components. For example, zonal wind $u$ can be decomposed as

$$
u=\bar{u}+u^{\prime}+u^{\prime \prime}+\varepsilon
$$

where the double prime denotes the 20-day high-pass filtered anomaly, and $\varepsilon$ denotes the residual due to the truncation error from the digital filtering. With this decomposition, the horizontal advection terms in Eq. (4) can be decomposed into nine terms as follows:

$$
\begin{aligned}
& -\left\langle u \frac{\partial q}{\partial x}\right\rangle^{\prime} \cong \underbrace{-\left\langle\bar{u} \frac{\partial \bar{q}}{\partial x}\right\rangle^{\prime}}_{\mathrm{T} 1} \underbrace{-\left\langle\bar{u} \frac{\partial q^{\prime}}{\partial x}\right\rangle^{\prime}}_{\mathrm{T} 2} \underbrace{-\left\langle\bar{u} \frac{\partial q^{\prime \prime}}{\partial x}\right\rangle^{\prime}}_{\mathrm{T} 3} \\
& \underbrace{-\left\langle u^{\prime} \frac{\partial \bar{q}}{\partial x}\right\rangle^{\prime}}_{\mathrm{T} 4} \underbrace{-\left\langle u^{\prime} \frac{\partial q^{\prime}}{\partial x}\right\rangle^{\prime}}_{\mathrm{T} 5} \underbrace{-\left\langle u^{\prime} \frac{\partial q^{\prime \prime}}{\partial x}\right\rangle^{\prime}}_{\mathrm{T} 6} \\
& \underbrace{-\left\langle u^{\prime \prime} \frac{\partial \bar{q}}{\partial x}\right\rangle^{\prime}}_{\mathrm{T} 7} \underbrace{-\left\langle u^{\prime \prime} \frac{\partial q^{\prime}}{\partial x}\right\rangle^{\prime}}_{\mathrm{T} 8} \underbrace{-\left\langle u^{\prime \prime} \frac{\partial q^{\prime \prime}}{\partial x}\right\rangle^{\prime}}_{\mathrm{T} 9}, \\
& -\left\langle\boldsymbol{v} \frac{\partial q}{\partial y}\right\rangle^{\prime} \cong \underbrace{-\left\langle\bar{v} \frac{\partial \bar{q}}{\partial y}\right\rangle^{\prime}}_{\mathrm{T} 1}-\underbrace{-\left\langle\bar{v} \frac{\partial q^{\prime}}{\partial y}\right\rangle^{\prime}}_{\mathrm{T} 2} \underbrace{-\left\langle\bar{v} \frac{\partial q^{\prime \prime}}{\partial y}\right\rangle^{\prime}}_{\mathrm{T} 3} \\
& \underbrace{-\left\langle v^{\prime} \frac{\partial \bar{q}}{\partial y}\right\rangle^{\prime}}_{\mathrm{T} 4} \underbrace{-\left\langle v^{\prime} \frac{\partial q^{\prime}}{\partial y}\right\rangle^{\prime}}_{\mathrm{T} 5} \underbrace{-\left\langle v^{\prime} \frac{\partial q^{\prime \prime}}{\partial y}\right\rangle^{\prime}}_{\mathrm{T} 6} \\
& \underbrace{-\left\langle v^{\prime \prime} \frac{\partial \bar{q}}{\partial y}\right\rangle^{\prime}}_{\mathrm{T} 7} \underbrace{-\left\langle v^{\prime \prime} \frac{\partial q^{\prime}}{\partial y}\right\rangle^{\prime}}_{\mathrm{T} 8} \underbrace{-\left\langle v^{\prime \prime} \frac{\partial q^{\prime \prime}}{\partial y}\right\rangle^{\prime}}_{\mathrm{T} 9} .
\end{aligned}
$$

Note that we show all terms in Fig. 2, but the terms that are much smaller than the other terms are omitted in Fig. 11.

\section{Results}

\section{a. Moistening processes during the MJO's passage across the maritime continent}

Figure 1 shows OLR and moisture tendency anomalies in lag days when MJO convection matures in the equatorial IO (Fig. 1a) and travels across the MC region (Figs. 1b-d). Unlike the structure of OLR anomalies in IO, which is almost symmetric to the equator, MJO convection in the vicinity of $\mathrm{MC}$ is highly asymmetric, with much stronger OLR anomalies being located to the south of the equator (Figs. 1c,d). This southward "detouring" of MJO around the MC during boreal winter has long been recognized (e.g., Wang and Rui 1990) and has been a subject of active research recently (e.g., Kim et al. 2017; Zhang and Ling 2017; D. Kim et al. 2020; Jiang et al. 2020). Kim et al. (2017) highlighted the difference in the amount of MSE recharging before the onset of MJO convection between the equatorial MC and SMC regions and suggested that the differential moistening causes MJO to have more pronounced anomalous convection to the south of the equator. Consistent with what was shown in Kim et al. (2017), moisture recharging (i.e., positive moisture tendency) occurs primarily in the 


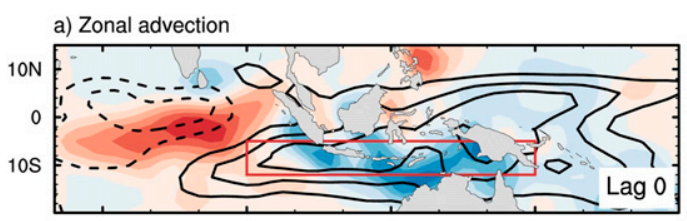

b) Meridional advection
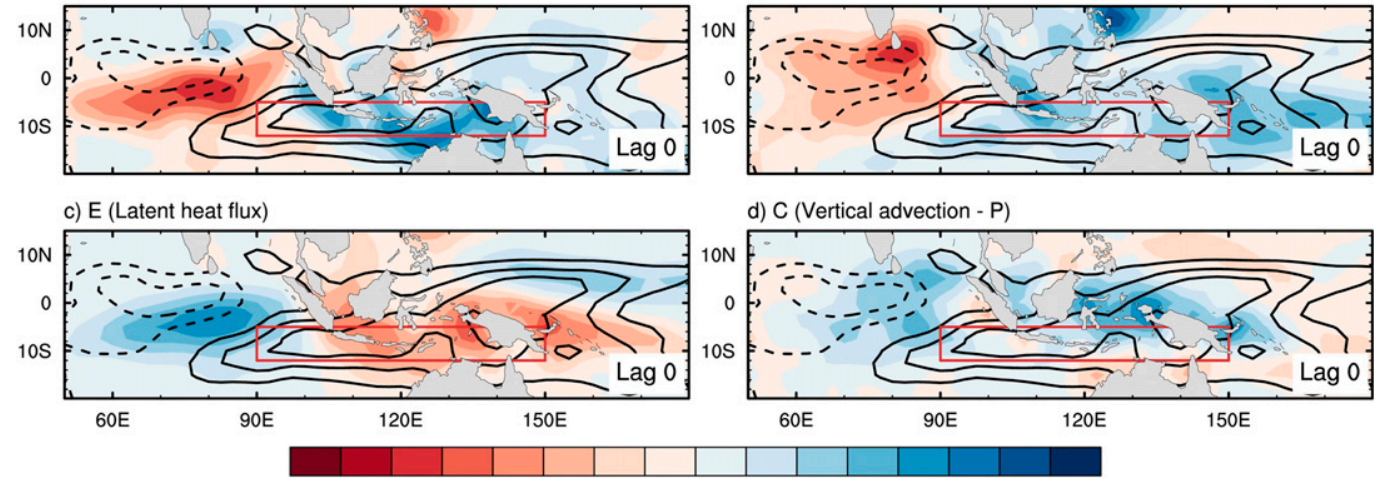

d) $\mathrm{C}$ (Vertical advection - P)

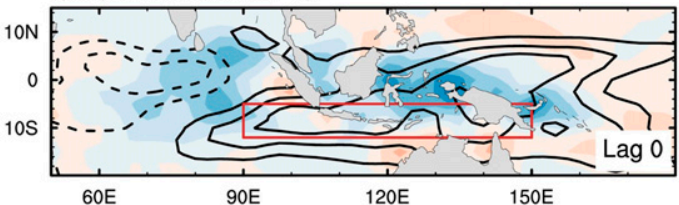

$\begin{array}{lllllllllllllll}-0.7 & -0.6 & -0.5 & -0.4 & -0.3 & -0.2 & -0.1 & 0 & 0.1 & 0.2 & 0.3 & 0.4 & 0.5 & 0.6 & 0.7\end{array}$
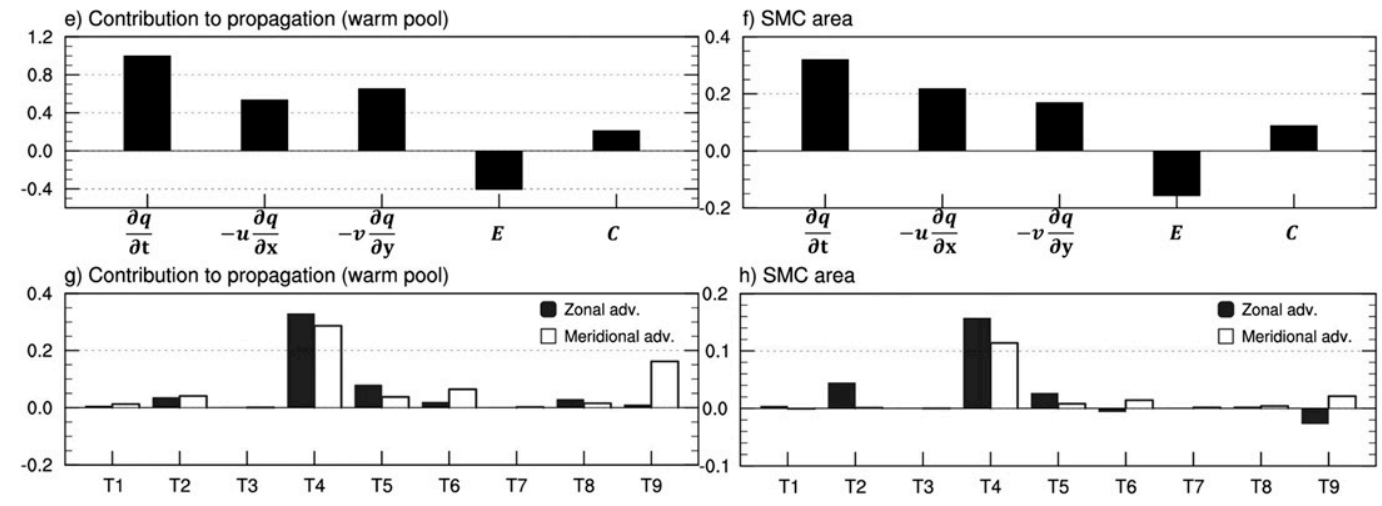
h) SMC area

FIG. 2. (a)-(d) As in Fig. 1a, except that each moisture budget term on lag day 0 is shaded. (e) Pattern similarity $\left[S_{X}\right.$; Eq. (8)] between each moisture budget term and the total moisture tendency over the Indo-Pacific warm pool $\left(15^{\circ} \mathrm{S}-15^{\circ} \mathrm{N}, 60^{\circ}-180^{\circ} \mathrm{E}\right)$. (f) The regression coefficient of the moisture budget terms averaged in the SMC [12.5 $5^{\circ} \mathrm{S}, 90^{\circ}-150^{\circ} \mathrm{E}$; the red box in (a)-(d)]. (g),(h) As in (e) and (f), but for the horizontal advection terms decomposed into different time scales of horizontal wind and moisture gradient as described in section $2 \mathrm{~d}$. The terms shown in the bar graphs are obtained using anomalies that are weighted by $1 /\left[\overline{\tau_{c}}\right]$.

meridionally narrow band in $\mathrm{SMC}\left(90^{\circ}-150^{\circ} \mathrm{E}, 12^{\circ}-5^{\circ} \mathrm{S}\right.$; red box in Fig. 1a) about 10-15 days before MJO convection peaks there (Figs. 1c,d).

To identify the processes responsible for the moisture recharging in the SMC region, Fig. 2 examines individual moisture budget terms during the time when the moisture recharging is most pronounced (lag day 0 ). The relative contribution of moisture budget terms in Eq. (4) is analyzed by examining the large-scale patterns of each term (Figs. 2e,g) and by quantifying the amount of moistening over the SMC region (Figs. 2f,h).

Figure 2 shows that the large-scale patterns of the horizontal advection terms closely resemble that of the total moisture tendency with the same polarity (Figs. 2a,b), while latent heat flux anomalies appear to oppose the total moisture tendency (Fig. 2c). The column process also enhances moisture tendency in the MC area, although it peaks near the equator and exhibits only small values in the SMC (Fig. 2d). In Figs. 2e and 2g, as in Andersen and Kuang (2012), the similarity between the large-scale pattern of individual moisture budget terms in Eq. (4) and that of the total moisture tendency is quantified using a pattern projection method:

$$
S_{X}=\frac{\left\|X^{\prime} \partial_{t} P^{\prime}\right\|}{\left\|\left(\partial_{t} P^{\prime}\right)^{2}\right\|},
$$

where $X$ is each moisture budget term and $\partial_{t} P$ is the moisture tendency. The expression $\|\cdot\|$ denotes the integral over the IndoPacific warm pool domain $\left(60^{\circ}-180^{\circ} \mathrm{E}, 15^{\circ} \mathrm{S}-15^{\circ} \mathrm{N}\right)$. We use the regression coefficients for each moisture budget term at lag day 0 . A positive $S_{X}$ for a term $X$ indicates that the term positively contributes to the total moisture tendency.

It is shown in Fig. 2e that the horizontal advection terms dominantly contribute to the total moisture tendency, suggesting their key role in the eastward movement of MJO moisture anomalies. The dominant role of horizontal advection terms has been repeatedly shown in the studies that examined MSE or moisture budget of the MJO (Maloney 2009; Kiranmayi and Maloney 2011; Andersen and Kuang 2012; Adames 2017; Jiang 2017). The column process weakly contributes to the moistening and drying, while latent heat flux anomalies seem to obstruct the eastward propagation of MJO moisture anomalies. This negative role of latent heat flux anomalies is consistent with the argument that the windevaporation feedback tends to drag eastward propagation of the MJO (Sobel et al. 2010). 
To further examine which physical process is responsible for the horizontal advection that dominates the moisture recharging, the horizontal advection terms are decomposed using the method described in section $2 d$. Figure $2 g$ shows the result of applying the pattern projection method to the individual terms. $\mathrm{T} 4$ is the largest term for both zonal and meridional advection, indicating that advection of the mean moisture by intraseasonal wind anomalies is the key component. In many previous observational and modeling studies, this term has been demonstrated as a dominant process in the horizontal moisture advection associated with the MJO (Maloney 2009; Kiranmayi and Maloney 2011; Jing Feng et al. 2015; Adames 2017; Jiang 2017; Wang et al. 2017; DeMott et al. 2018; Jiang et al. 2018; Ahn et al. 2020a). T9 is the second largest term for the meridional advection, which is associated with anomalous meridional moisture advection by the high-frequency eddies (Kiranmayi and Maloney 2011; Andersen and Kuang 2012; Benedict et al. 2015; Jiang 2017). It has been shown that the high-frequency eddy activity is affected by the intraseasonal wind anomalies through the barotropic energy conversion from the MJO flow to the synoptic-scale disturbances (Maloney and Hartmann 2001). Since the eddies tend to transport moisture poleward, increased (decreased) eddy activity corresponds to anomalous drying (moistening) in the equatorial region. In the equatorial warm pool area, the moistening (drying) anomalies associated with modulation of the high-frequency eddy activity tend to occur to the east (west) of MJO convection (Maloney 2009).

Next, we examine each moisture budget term averaged in the $\mathrm{SMC}$ region to focus on the local moistening process. Figure $2 \mathrm{f}$ indicates that the zonal and meridional moisture advection terms are the main moistening processes, with a weak positive contribution from the column process and a sizable negative contribution from latent heat flux. The result for the decomposed horizontal advection terms shows that the advection of the mean moisture by intraseasonal wind anomalies (T4) predominantly contribute to the horizontal advection, while T9 of meridional advection seems to be less influential in the SMC than that shown in the large-scale pattern (Fig. 2h).

The above results show that, regardless of the method employed (i.e., the local average versus the pattern projection), the advection of the mean moisture by MJO perturbation wind is identified as the key moistening process in the SMC region before the onset of MJO convection there. Given that the dominant process for the propagation of MJO moisture anomalies (i.e., T4) involves the mean moisture gradient, it is reasonable to hypothesize that a higher mean moisture gradient in that region would lead to an enhanced $\mathrm{MJO}$ activity. While both zonal and meridional advection are found to be the key process in Fig. 2, in the following we focus on the meridional gradient of the mean state moisture and its role on the year-to-year variability of the MJO. This is motivated by the results of the observational (DeMott et al. 2018) and modeling (Gonzalez and Jiang 2017; DeMott et al. 2019; Ahn et al. 2020a,b; Kang et al. 2020) studies that highlighted the meridional gradient of the mean moisture. Jiang (2017) showed that the T4 component of meridional advection in models with the good MJO simulation is much
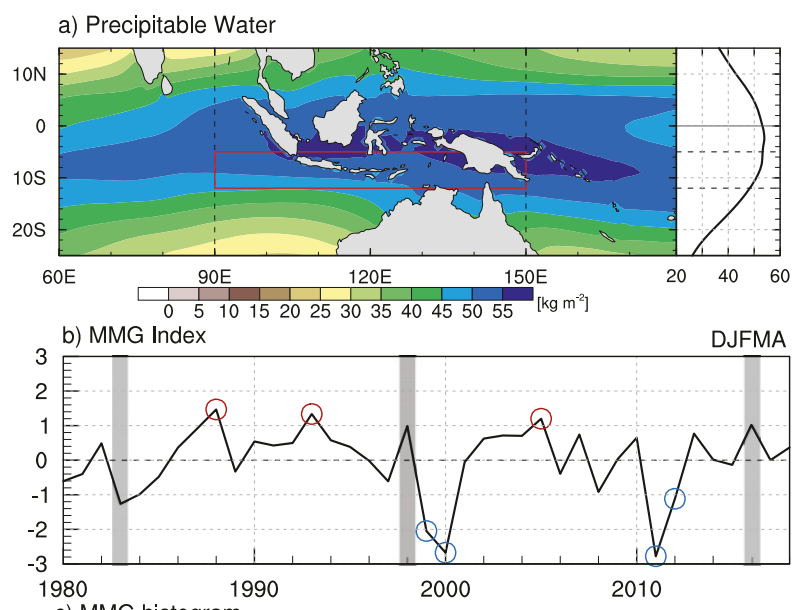

c) MMG histogram

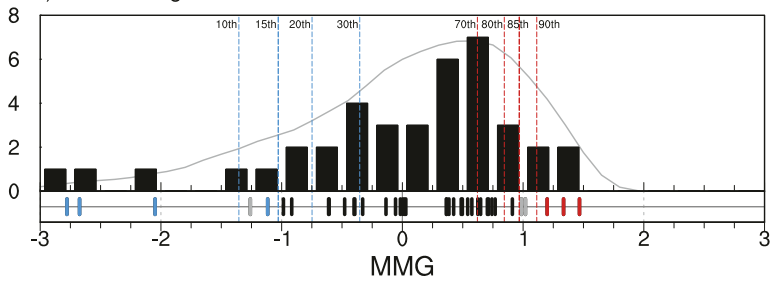

FIG. 3. (a) Climatological mean of precipitable water (contour; $\mathrm{kg} \mathrm{m}^{-2}$ ) for DJFMA 1980-2018. The panel on the right shows the distribution of zonally averaged $\left(90^{\circ}-150^{\circ} \mathrm{E}\right)$ precipitable water as a function of latitude. (b) Time series of the MMG index (see text for definition). Red and blue circles indicate the high- and low-MMG years, respectively. Extreme El Niño events are marked with gray shading. (c) The histogram of the MMG index. The vertical markers at the bottom indicate the MMG index of each year. The red (70th, 80th, 85 th, and 90th percentile) and blue (10th, 15th, 20th, and 30th percentile) vertical dashed lines indicate percentile values obtained from a skewed distribution (gray line).

greater than those with the poor MJO simulation, while their difference is less pronounced in the T4 component of zonal advection.

\section{b. Background moisture gradient in the $M C$ region and its interannual variability}

Figure 3a illustrates the climatological mean PW (i.e., total column water vapor) in DJFMA. The mean state PW exhibits abundant moisture over the Indo-Pacific warm pool, especially in the vicinity of the MC. In terms of the meridional structure across the IO and MC (right panel of Fig. 3a), PW values higher than $50 \mathrm{~kg} \mathrm{~m}^{-2}$ appear mostly between $10^{\circ} \mathrm{S}$ and $5^{\circ} \mathrm{N}$, the channel through which MJO convection propagates. As the mean moisture gradually decreases poleward from its maximum value located between the equator and $5^{\circ} \mathrm{S}$, the meridional gradient of the mean moisture tends to be a positive (negative) value in the Southern (Northern) Hemisphere. In the SMC region $\left(12^{\circ}-5^{\circ} \mathrm{S}\right)$, the mean moisture begins to decrease poleward more rapidly.

To examine the relationship between the mean moisture gradient in the SMC with the characteristics of MJO 

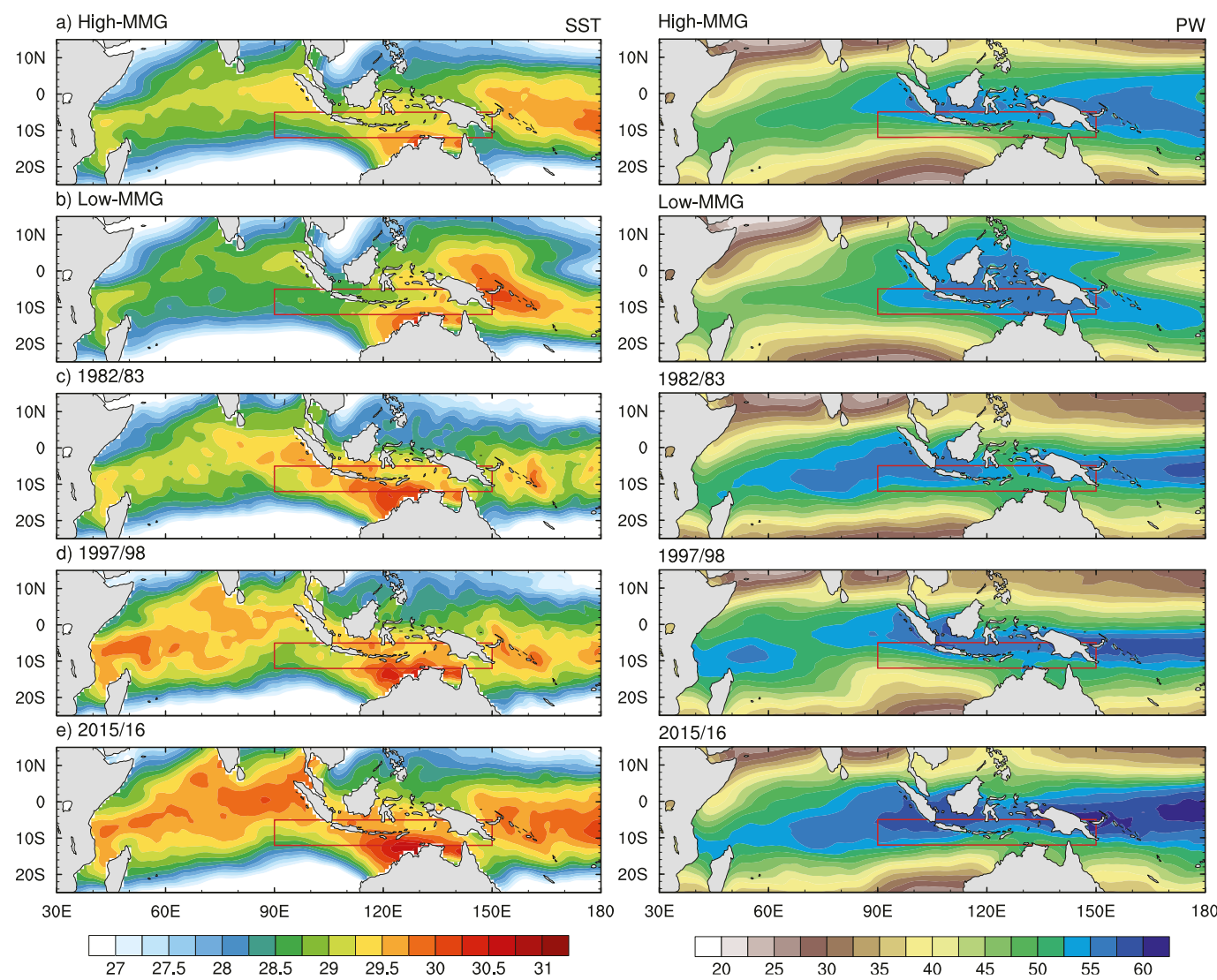

FIG. 4. Composites of seasonal-mean (DJFMA) (left) SST and (right) PW during the (a) high-MMG years and (b) low-MMG years. (c)-(e) As in (a), but for extreme El Niño events: (c) 1982/83, (d) 1997/98, and (e) 2015/16. The red box indicates the domain used for the MMG index.

propagation, we define an index that characterizes the seasonal mean MMG over the SMC. To obtain the MMG index, we first average MMG of DJFMA-mean PW over the SMC region and then normalize the resulting time series by its mean and standard deviation. Figure $3 \mathrm{~b}$ shows the time series of the MMG index for the period of 1979-2018. For convenience, each DJFMA season is denoted by the year of the January. For example, 1980 on the $x$ axis of Fig. 3b indicates the 1979/ 80 winter. Figure $3 \mathrm{c}$ shows the histogram of the MMG index, which exhibits a negatively skewed distribution (skewness: -1.08); there are many years with weak positive MMG (between 0.5 and 1 ), with a few years showing much stronger negative values.

To compare the mean state and MJO propagation characteristics between years with relatively high and low background MMG, we first created 10000 skewed random samples (Azzalini and Capitanio 1999) with the same mean, standard deviation, and skewness as those of the MMG index. We then chose the 15 th and 85 th percentiles from the skewed random samples as the thresholds for abnormal MMG years (marked as the thick dashed lines in Fig. 3c). The 15 th and 85 th percentiles are chosen by considering that about $15 \%$ of samples reside in the normal distribution outside plus and minus one standard deviation, respectively.
We note that the following results are robust unless the thresholds are loosened to include many years with a weak MMG anomaly (Fig. S2).

Using the threshold values that correspond to the 15 th and 85th percentiles, we first examine the seasonal mean SST and PW in the individual years with strong MMG anomalies. Inspections of PW anomalies in each of these years (Fig. S3) reveal that they tend to exhibit a symmetric pattern to the equator, except for 1982/83, 1997/98, and 2015/16 (marked as gray in Figs. 3b,c). Interestingly, all three years in which PW anomalies are highly asymmetric to the equator are the socalled extreme El Niño events (Santoso et al. 2017), which are distinguished from "normal" El Niño years by excessive SST anomalies in the tropical Pacific Ocean. Figure 4 compares the mean state changes in the extreme El Niño years with those for the other high-MMG (1988, 1993, and 2005) and low-MMG yeas $(1999,2000,2011$, and 2012). When compared to the other high-MMG and low-MMG years, the three extreme El Niño events exhibit much stronger warming throughout the Indo-Pacific warm pool (Fig. 4). More importantly, the changes in the mean $\mathrm{PW}$ in the extreme El Niño years are also much more pronounced in the IO and northwest Pacific rather than in the SMC, and the mean PW patterns in the IO vary from one event to another. For 
(a) High MMG

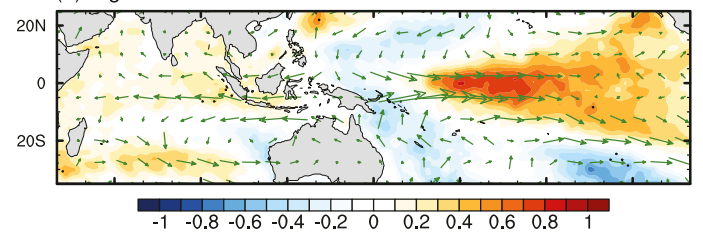

(c)

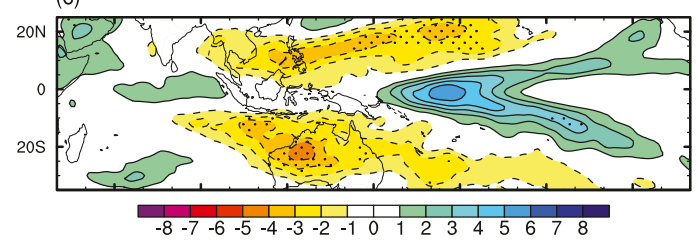

(b) Low MMG

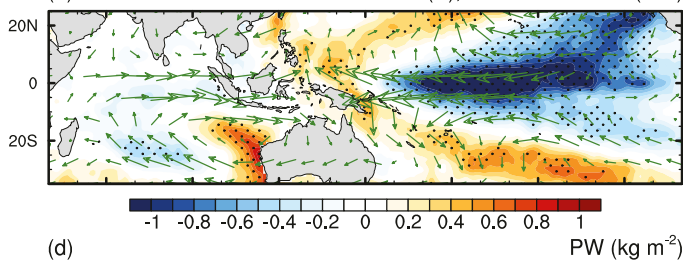

SST $(\mathrm{K})$, Wind at $850 \mathrm{hPa}(\mathrm{m} / \mathrm{s})$

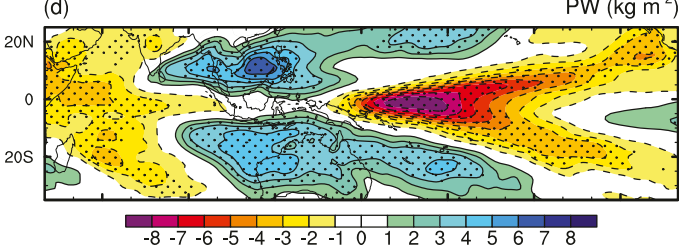

FIG. 5. Composites of seasonal-mean (DJFMA) SST (K; shaded), and low-level wind ( $850 \mathrm{hPa} ; \mathrm{m} \mathrm{s}^{-1}$; vectors) anomalies during (a) the high-MMG years and (b) the low-MMG years. (c),(d) As in (a) and (b), but for precipitable water $\left(\mathrm{kg} \mathrm{m}^{-2}\right)$. Areas with black dots indicate anomalies are statistically significant at the $95 \%$ confidence level in a two-sided Student's $t$ test.

example, in the 1982/93 and 2015/16 El Niño events, PW is much higher than normal in most of the southern IO, while the zonal gradient of PW becomes much weaker between $15^{\circ}$ and $5^{\circ} \mathrm{S}$ in 1997/98 El Niño event. These peculiar anomalous patterns can be associated with a shift of the ascending branch of the Walker circulation toward the far eastern Pacific than during the moderate El Niño events (e.g., Wang and Wang 2014).

The above discussion reveals that, during the extreme El Niño events, MJO characteristics can be affected by the mean moisture anomalies in the IO, as well as those in SMC. For example, the strong changes in the IO SST and PW associated with the extreme El Niño events can affect the frequency, pattern, and strength of MJO convection over the IO (e.g., Benedict et al. 2015), which could interfere with the effect of MMG in the SMC region. Because the seasonal-mean background states during the extreme El Niño events exhibit excessive moisture anomalies out of the SMC region rather than in the SMC (Fig. 4), the extreme El Niño events are excluded from the following analysis. The impacts of the distinct pattern of excessive moisture anomalies in each extreme El Niño event on the MJO warrants further investigation.

Figure 5 compares the seasonal mean anomalies of SST, lowlevel wind, and PW for high-MMG and low-MMG years. In the high-MMG years, the SST anomalies exhibit an El Niño-like pattern with positive anomalies in the central-eastern Pacific Ocean, and negative anomalies in the western Pacific Ocean and the subtropical region in the CP (Fig. 5a). Weak basinwide warming appears in the IO, except in the southeast IO, where SST anomalies are negative. The low-level wind anomalies show a zonally diverging and meridionally converging circulation around the MC (Fig. 5a). PW anomalies exhibit a pattern similar to that of the SST anomalies, while being more symmetric about the equator (Fig. 5c). In the vicinity of the MC, meridionally symmetric dry anomalies appear to the north and south of the MC, which correspond to the steeper MMG at the off-equatorial region.
The patterns of SST, low-level wind, and PW anomalies in the low-MMG years resemble those in the high-MMG years, albeit with the opposite sign. There are some notable differences between the two patterns, however. Overall, the anomalies in the low-MMG years are slightly shifted to the west with a stronger amplitude (Figs. 5b,d). The SST pattern in the low-MMG years resembles the "warm pool dipole" mode proposed by Zhang and Han (2020), who suggested that the SST anomalies associated with the warm pool dipole mode provide an unfavorable condition for MJO propagation across the MC (Zhang and Han 2020). Also, the warm anomalies in the southeast IO seem to be associated with the Ningaloo Niño, an abnormal SST condition in that region that is known to occur in association with the enhanced poleward transport of warm tropical water via the strengthening of the Indonesian Throughflow and Leeuwin Current (Feng et al. 2011, 2013). Indeed, the two years with the lowest MMG value (2000 and 2011) are years with a strong Ningaloo Niño event (M. Feng et al. 2015).

Considering that PW climatologically peaks around the equator $\left(\sim 2^{\circ} \mathrm{S}\right)$ in the $\mathrm{MC}$ region, negative $\mathrm{PW}$ anomalies straddling the equator would steepen the meridional gradient of moisture along the MC in both hemispheres. In the composites, $\mathrm{PW}$ is lower in the high-MMG years than in the climatology to the south of $5^{\circ} \mathrm{S}$ and to the north of $5^{\circ} \mathrm{N}$ (Fig. 6a). As a result, the meridional gradient in the SMC region becomes sharper (Fig. 6b). In contrast, in the low-MMG years, the background meridional gradient of PW has lower absolute values with an anomalous wet and dry condition in the off-equatorial region and near $2^{\circ} \mathrm{S}$, respectively.

In this subsection, we have shown that the meridional extent of the "moist pool" in the vicinity of the MC expands and shrinks meridionally in association with SST anomalies in the tropics. The changes in the meridional extent of the moist pool systematically change the MMG in the SMC region, the key area for $\mathrm{MJO}$ propagation (section $3 \mathrm{a}$ ). 

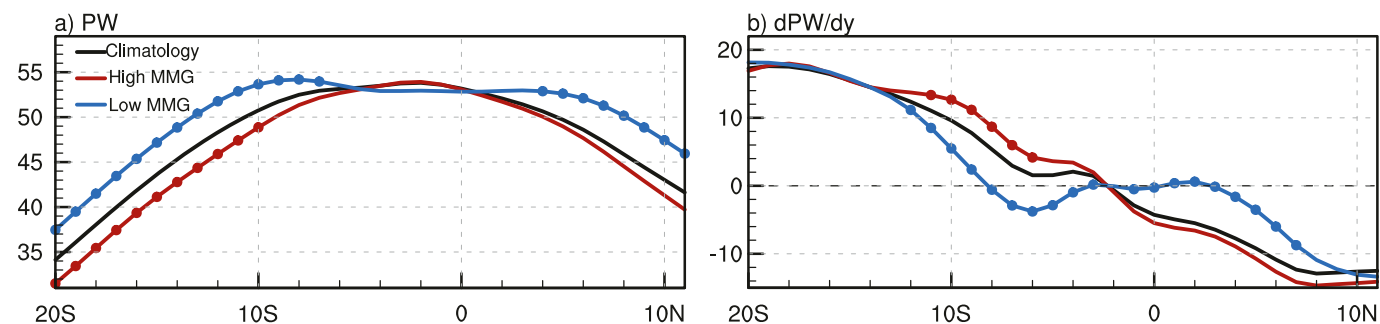

FIG. 6. (a) Meridional distribution of the precipitable water $\left(\mathrm{kg} \mathrm{m}^{-2}\right)$ averaged over $90^{\circ}-150^{\circ} \mathrm{E}$ for all years (black), the high-MMG years (red), and the low-MMG years (blue). (b) As in (a), except for the meridional gradient of precipitable water $\left(10^{6} \mathrm{~kg} \mathrm{~m}^{-3}\right)$. The dots on each line indicate that the deviations from the all-year results are statistically significant at the $95 \%$ confidence level in a two-sided Student's $t$ test.

The close association between the MMG in the SMC and the large-scale SST and circulation anomalies strongly suggests that anomalies in the MMG can be considered as an external forcing to the MJO. In the next section, we compare $\mathrm{MJO}$ propagation characteristics between the high- and low-MMG years. If a higher mean MMG indeed provides a favorable condition for $\mathrm{MJO}$ propagation, one would expect a smoother, more coherent MJO propagation through the MC in the high-MMG years than in the low-MMG years.

\section{c. MMG as a key modulator of MJO propagation over the $M C$}

To examine MJO propagation characteristics, we first compared the time evolution of an OLR-based MJO index (OMI; Kiladis et al. 2014) between the high-MMG and
low-MMG years. Figure 7a shows a phase diagram of OMI regressed onto the OLR anomalies in the IO base point during the high- and low-MMG years. The initial MJO amplitude (i.e., the distance from the origin in the phase diagram) is much larger in the high-MMG years than in the low-MMG years (Fig. 7a). As the MJO events propagate eastward (i.e., counterclockwise rotation in the phase diagram) and pass the $\mathrm{MC}$ region, there is a sharp contrast in the behaviors of the MJO between the high-MMG and lowMMG years. While the MJO convection in the high-MMG years tends to maintain its initial amplitude, the $\mathrm{MJO}$ amplitudes quickly decrease as the MJO moves through the MC in the low-MMG years. We find that MJO tends to be more strongly damped over the MC in the low-MMG years than in the high-MMG years even when normalized by the initial amplitude (Fig. 7b). a) OMI phase diagram

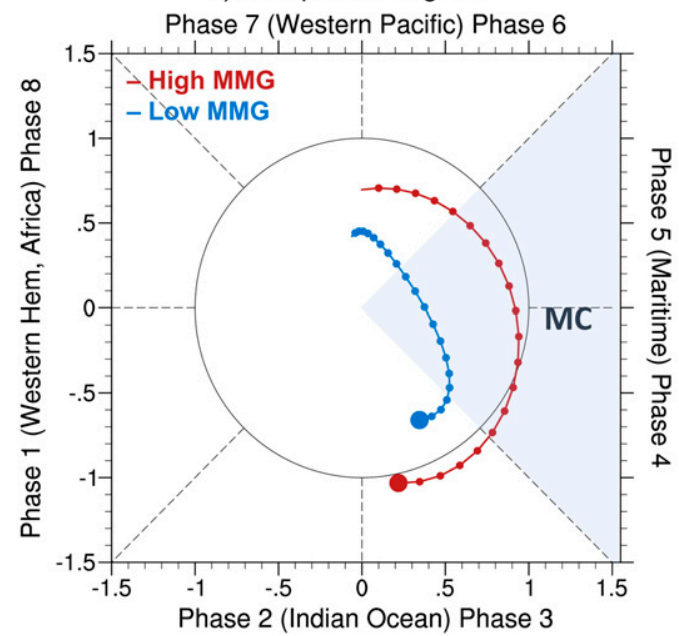

b) normalized by amplitude on day 0

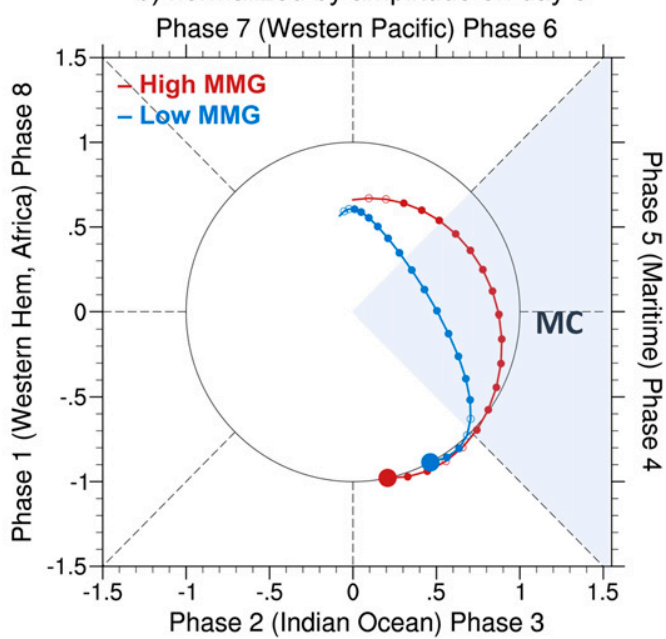

FIG. 7. (a) Phase space representation of OMI1 and OMI2 regressed onto the reference OLR time series from the IO base point $\left(5^{\circ} \mathrm{S}-5^{\circ} \mathrm{N}, 75^{\circ}-85^{\circ} \mathrm{E}\right)$. The larger circles at the lower edge of the curves indicate lag day 0 . The lag days on which the difference in OMI1 or OMI2 between the high- and low-MMG years is statistically significant at the $95 \%$ confidence level are marked with filled circles. The significance testing is performed separately for OMI 1 and OMI 2 with the $t$ values for the testing being obtained as the difference in the regression coefficients divided by the square root of the sum of standard deviations. (b) As in (a), but for the regressed OMI values that are scaled by the OMI amplitude (i.e., distance from the center) on lag 0. 
Figure 8 shows the time evolution of OLR and low-level zonal wind anomalies in a near-equatorial latitude band $\left(15^{\circ} \mathrm{S}-\right.$ $5^{\circ} \mathrm{N}$ ). In both groups, anomalous convection coupled with lowlevel zonal wind anomaly exhibits an eastward propagation from the IO to the MC (Figs. 8a,b). The eastward propagation of the MJO is more prominent in the high-MMG years than that in the low-MMG years. The two groups of MJO events exhibit a notable amplitude difference in the anomalies, especially to the east of the western end of the $\mathrm{MC}$ region $\left(100^{\circ} \mathrm{E}\right.$; Fig. 8c). In the high-MMG years, the MJO propagates through the $\mathrm{MC}$ with enhanced convection, while the MJO convection in the low-MMG years weakens rapidly in the MC. This remarkable difference in the MC is consistent with the above results with the OMI phase diagrams (Fig. 7), highlighting the crucial role of the mean state MMG on MJO convection in the MC.

Given the notable difference in the amplitude of the $\mathrm{MJO}$ in the $\mathrm{MC}$ region, one might suspect that the difference in $\mathrm{MJO}$ activity could affect the mean state. To test whether and to what extent the difference in the mean state (i.e., MMG) between the high- and low-MMG years is affected by the difference in MJO characteristics, we compared the mean state calculated using all days with that obtained after removing the strong MJO days. For this analysis, we used both the real-time multivariate MJO (RMM; Wheeler and Hendon 2004) index and the OMI to define the strong MJO days. The days with an amplitude of the MJO indices greater than 1.5 were excluded to calculate the mean state without the strong MJO. The numbers of excluded days account for $38 \%$ and $41 \%$ for RMM and OMI, respectively. Figure 9 shows that the differences in the pattern and magnitude of PW anomalies between the high- and low-MMG years are only weakly affected by the exclusion of the strong MJO days. Regardless of the MJO index used to filter out strong MJO days, the MMG indices obtained with and without the strong MJO days are highly correlated (Fig. S4). This result strongly suggests that the difference in background moisture gradient between the high-MMG and low-MMG years is not driven by the difference in the MJO behavior.

To identify the specific role of the mean state MMG on MJO activity in the MC during the high- and low-MMG years, horizontal patterns of OLR and column-integrated moisture tendency anomalies are compared (Fig. 10). The OLR anomalies exhibit a notable difference between high-MMG and low-MMG years, especially in the SMC (lag days 5-15). In the high-MMG years, the strength of MJO convection is maintained as it reaches the MC (lag days 0-10), and MJO convection along the SMC continues to propagate eastward with a strong amplitude to the equatorial WP (lag days 10-20). In contrast, MJO convection during the lowMMG years tends to peak in the eastern IO, then the anomalous convection rapidly weakens in the SMC (lag days 5-15).

Also shown in Fig. 10 are the total moisture tendency anomalies. On lag day 0 , positive moisture tendency anomalies appear in the equatorial MC and SMC in both high-MMG and low-MMG years. In the high-MMG years, the positive moisture tendency anomalies are strongest over the SMC (the red box in Fig. 10a), which are much weaker in the low-MMG years (Fig. 10b). The weaker moisture recharging in the SMC a) High MMG
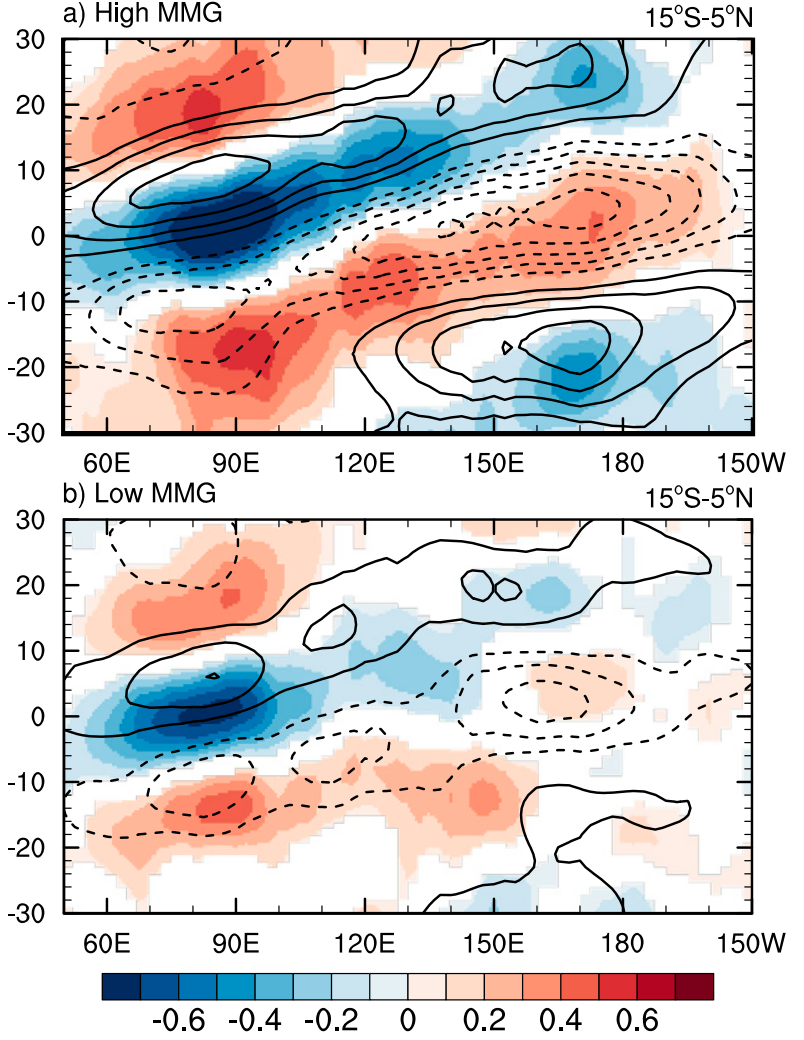

c) Difference $(a-b)$

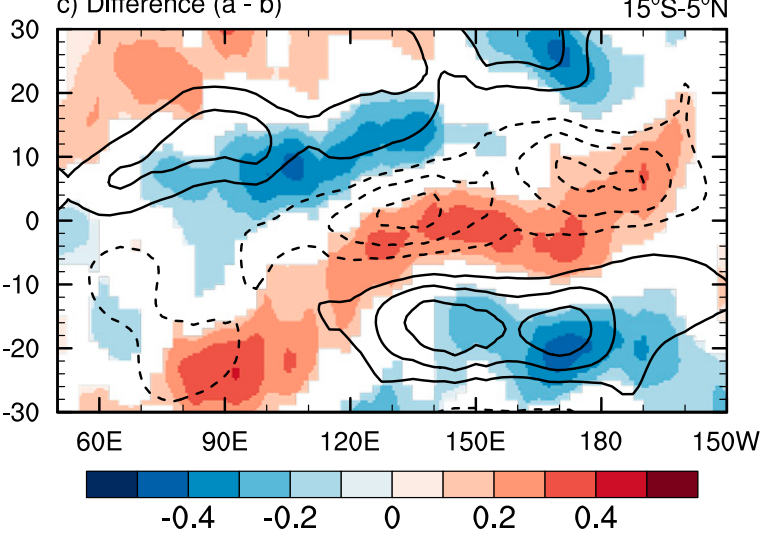

FIG. 8. Longitude-time evolution of 20-100-day bandpassfiltered OLR ( $\mathrm{W} \mathrm{m}^{-2}$; shaded) and $850-\mathrm{hPa}$ zonal wind $\left(\mathrm{m} \mathrm{s}^{-1}\right.$; contour) anomalies near the equator $\left(15^{\circ} \mathrm{S}-5^{\circ} \mathrm{N}\right.$ averaged) during (a) the high-MMG years and (b) the low-MMG years. Data were obtained from the lag regressions of the variables onto the reference OLR time series from the IO base point $\left(5^{\circ} \mathrm{S}-5^{\circ} \mathrm{N}, 75^{\circ}-85^{\circ} \mathrm{E}\right)$. In all panels, OLR anomalies that are statistically significant at the 95\% confidence level are presented.

seems to be causing the rapid decay of MJO convection anomalies across the $\mathrm{MC}$ region (lag days 5-15).

To understand the relative roles of each moisture budget term on the difference in total moisture tendency between the highand low-MMG years, the moisture budget of the MJO is examined. Figure 11 presents the moisture budget terms in the 
(a) High MMG

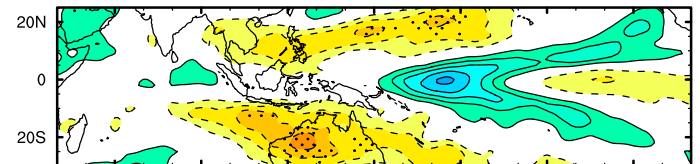

After removing the strong OMI days ( $41 \%$ of total days)

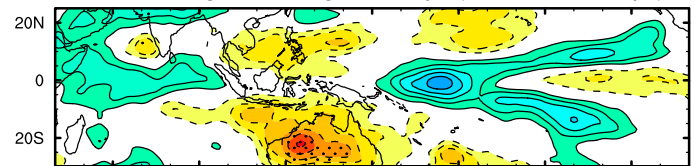

After removing the strong RMM days (38\% of total days)
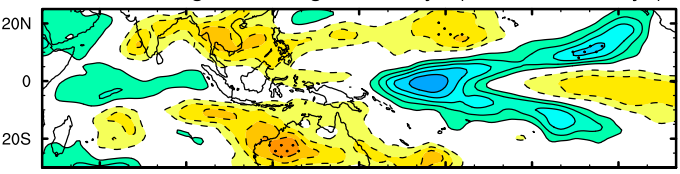

$60 \mathrm{E}$

120

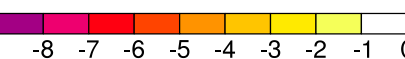

(b) Low MMG

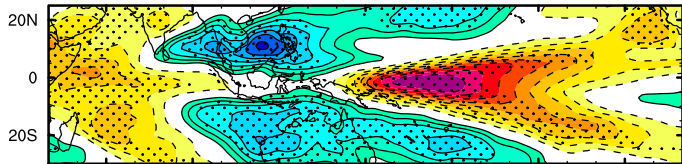

After removing the strong OMI days ( $41 \%$ of total days)

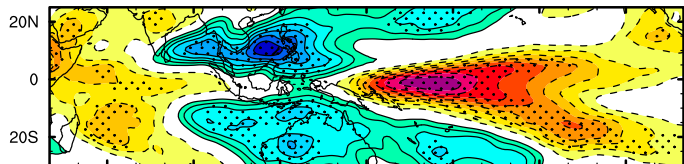

After removing the strong RMM days (38\% of total days)

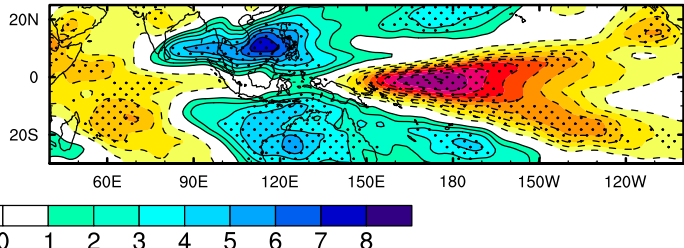

FIG. 9. (top) Composites of seasonal-mean (DJFMA) precipitable water $\left(\mathrm{kg} \mathrm{m}^{-2}\right)$ anomalies for (a) the highMMG years and (b) the low-MMG years. Also shown are the corresponding composite anomalies without the strong MJO days defined with (middle) OMI and (bottom) RMM. The strong MJO days are selected when the amplitude (i.e., root sum of squares of the two leading principal components) of each index is higher than 1.5. Black dots indicate anomalies are statistically significant at the $95 \%$ confidence level.

SMC $\left(12.5^{\circ}-5^{\circ} \mathrm{S}, 90^{\circ}-150^{\circ} \mathrm{E}\right.$; the red box in Fig. 10) during the moisture recharging period (lag days from -2 to 2 ). The total moisture tendency anomaly in the high-MMG years is $88 \%$ larger than that in the low-MMG years, and the meridional advection term dominantly contributes to the difference in the total moisture tendency between the high- and low-MMG years. In contrast, the zonal advection term shows a higher value in the low-MMG years, although its difference is statistically insignificant. The damping effect by latent heat flux is stronger in the high-MMG years, likely due to the more intense zonal wind anomalies in the SMC. The column process constructively contributes to the total moisture tendency only in the high-MMG years, which is associated with enhanced descending motion in the eastern part of the SMC domain (e.g., lag day 0 in Fig. 10a).

The dominant contribution of meridional advection to the total moisture tendency difference warrants an in-depth examination of the meridional advection term. Figure $11 \mathrm{~b}$ shows a few terms from the time scale decomposition of the meridional advection term (section $2 \mathrm{~d}$ ). Terms that are negligibly small have been omitted. The anomalously positive meridional advection in both high-MMG and low-MMG years (Fig. 11a) can primarily be attributed to the meridional advection of the mean moisture by intraseasonal wind anomalies (T4 in Fig. 11b). Although T6 and T9 partly contribute to the total meridional advection difference, their contributions are much smaller than that of T4 (Fig. 11b).

Figure 12a further examines the vertical profile of the meridional advection in the SMC during the moisture recharging period (lag days from -2 to 2 ). The total meridional moisture advection before the onset of MJO convection in the highMMG years exhibits a bottom-heavy profile with enhanced moisture recharging in the mid- to lower free troposphere $(850-500 \mathrm{hPa})$. In contrast, the anomalous moisture recharging by meridional advection in the low-MMG years is much smaller (Fig. 12a). In both high-MMG and low-MMG years, the T4 component makes up a significant portion (nearly $100 \%$ in the high-MMG years) of the total meridional moisture advection term above $800 \mathrm{hPa}$. Therefore, the vertical profiles of the intraseasonal wind anomalies and the mean state MMG, which compose the T4 term, can explain the difference in the meridional advection shown in Fig. 12a. While the stronger MJO-perturbed northerly wind anomalies in the high-MMG years appear only in a shallow layer around $650 \mathrm{hPa}$ (Fig. 12b), mean state moisture gradient is much steeper throughout all levels where the difference in the meridional advection term is pronounced (Fig. 12c).

The results presented in Figs. 11 and 12 strongly suggest that the greater moisture recharging by meridional advection in the high-MMG years is associated with the steeper background MMG in the SMC, with a smaller contribution from the stronger wind anomalies. Since the change in magnitude of MJO-perturbed wind anomalies is more likely to be a response to the change in MJO activity, the wind anomaly itself cannot explain the change in MJO activity. The mean state MMG, on the other hand, serving as the boundary condition for MJO, can be considered as an external factor. The changes in the MJO due to changes in the mean state MMG can be further enhanced by the change in the MJO-perturbed wind anomalies.

\section{Summary and conclusions}

Motivated by the recent studies that highlighted the role of the background moisture gradient on the propagation of the MJO in climate model simulations (Gonzalez and Jiang 2017; Jiang 2017; DeMott et al. 2019; Ahn et al. 2020b; Kang et al. 2020), this study examined the influence of the background 
a) High MMG

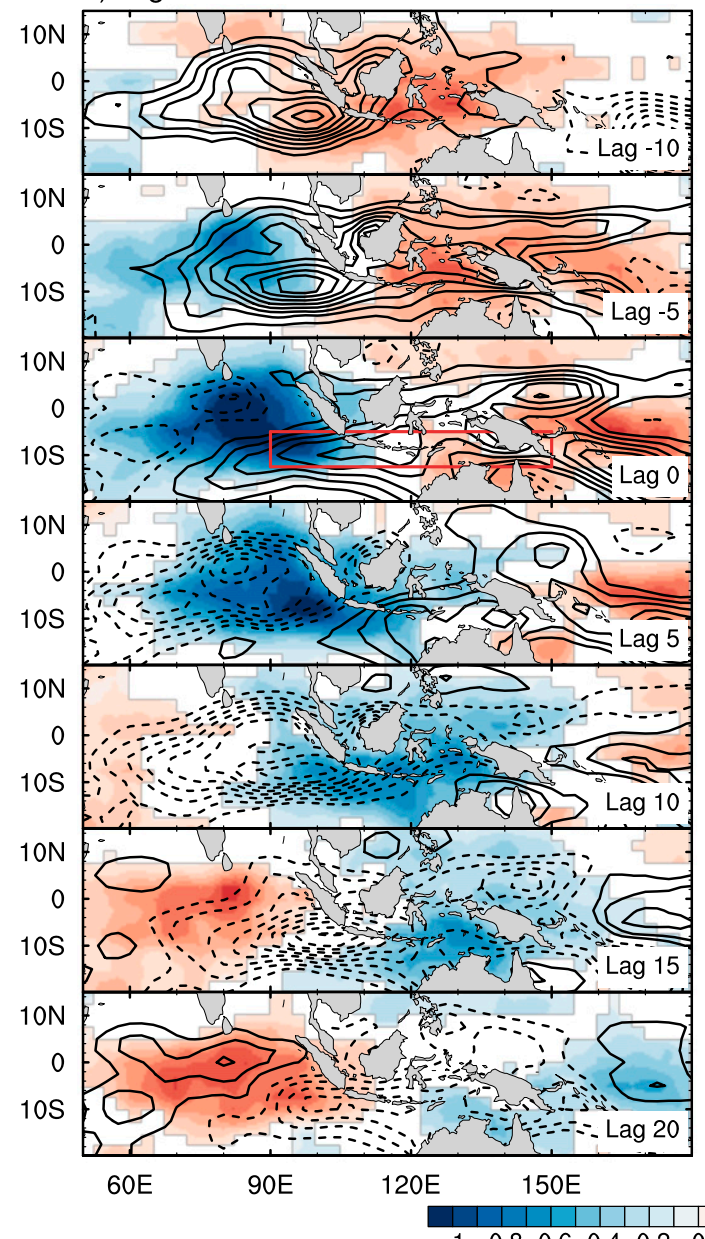

b) Low MMG

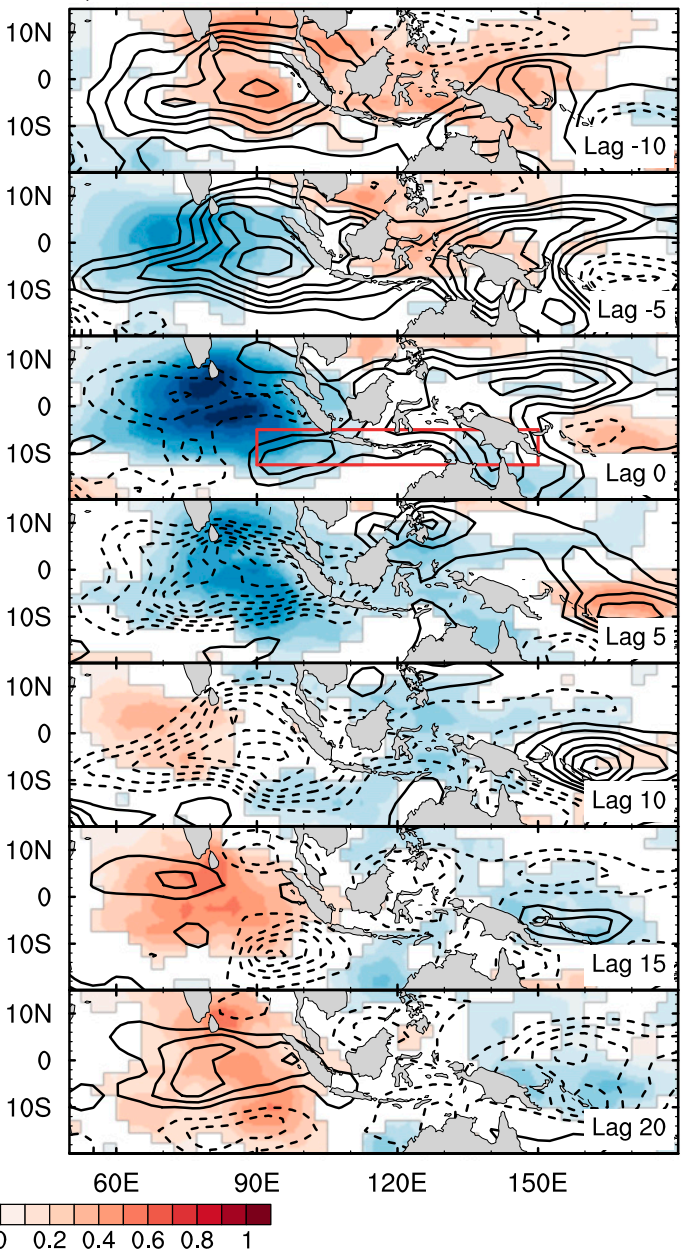

FIG. 10. Lagged regression of 20-100-day bandpass-filtered OLR ( $\mathrm{W} \mathrm{m}^{-2}$; shaded) and column-integrated moisture tendency anomalies ( $\mathrm{kg} \mathrm{m}^{-2}$; contour) during (a) the high-MMG years and (b) the low-MMG years. The column-integrated moisture tendency anomalies are spatially weighted by $1 /\left[\overline{\tau_{c}}\right]$. Data were obtained from lagged regression of the variables onto the reference OLR time series from the IO base point $\left(5^{\circ} \mathrm{S}-5^{\circ} \mathrm{N}, 75^{\circ}-85^{\circ} \mathrm{E}\right)$. Each row indicates lag days from -10 to 20 at a 5-day interval. The shaded anomalies are those that are statistically significant at the $95 \%$ confidence level.

MMG on MJO propagation at the interannual time scale during boreal winter (DJFMA). To aid our investigation, we defined an MMG index that represented the meridional gradient of seasonal mean $\mathrm{PW}$ in the SMC region $\left(90^{\circ}-150^{\circ} \mathrm{E}, 12^{\circ}-\right.$ $5^{\circ} \mathrm{S}$ ), where moisture recharging occurs primarily through the horizontal advection of the mean moisture when enhanced convection associated with the MJO approaches the MC.

The background MMG exhibited a marked interannual variability. In seeking large-scale factors that could influence the local moisture gradient in the SMC region, we examined SST, PW, and low-level circulation anomalies associated with the MMG index. The background MMG was found to be associated with large-scale SST and circulation anomalies, strongly suggesting that it is part of the low-frequency variability that is external to the MJO. The PW anomalies that were meridionally symmetric to the equator were accompanied by
SST anomalies in the vicinity of the MC. In the high-MMG years, with seasonal mean dry anomalies straddling the equator, seasonal mean PW decreased more sharply poleward from the equatorial MC. In contrast, during the low-MMG years, the meridional extent of the moist pool becomes wider, with a much weaker meridional gradient of PW in the SMC.

To examine how the changes in the background MMG affect the propagation of the MJO, we investigated the evolution of MJO convection after peaking in the eastern IO for both high-MMG and low-MMG years. The results showed that the behavior of the $\mathrm{MJO}$ over the $\mathrm{MC}$ region showed a marked difference between the high- and low-MMG years. In the high-MMG years, MJO convection from the eastern IO maintained its amplitude while propagating across the $\mathrm{MC}$ region. In the low-MMG years, on the contrary, the MJO amplitude quickly weakened over the MC. 
a) Moisture budget

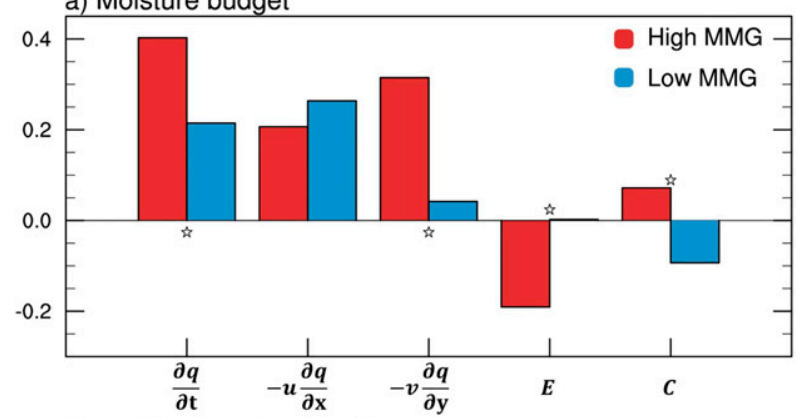

b) Meridional advection decomposition

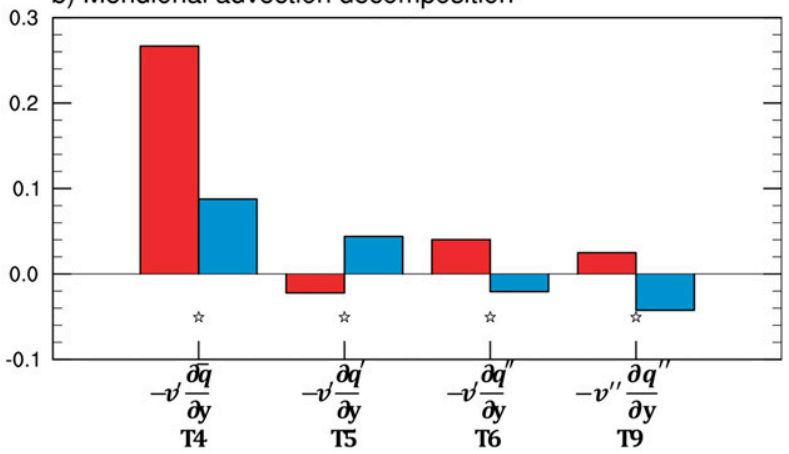

FIG. 11. (a) Moisture budget terms in the SMC $\left(12.5^{\circ}-5^{\circ} \mathrm{S}, 90^{\circ}-\right.$ $150^{\circ} \mathrm{E}$; the red box in Fig. 10) averaged over lag days from -2 to 2 in the high-MMG years (red) and the low-MMG years (blue). Data were obtained from lagged regression of the variables onto the reference time series of 20-100-day bandpass-filtered OLR anomalies $\left(\mathrm{W} \mathrm{m}^{-2}\right)$ averaged in the IO base point $\left(5^{\circ} \mathrm{S}-5^{\circ} \mathrm{N}, 75^{\circ}-\right.$ $\left.85^{\circ} \mathrm{E}\right)$. The star indicates that the difference between the high- and low-MMG years is statistically significant at the $95 \%$ confidence level. (b) As in (a), but for the meridional advection term decomposed into different time scales of meridional wind and moisture gradient as described in section $2 \mathrm{~d}$. The decomposed terms of very small values are omitted. As denoted in Eq. (4), the terms shown in the bar graph are column-integrated, 20-100-day bandpass-filtered and spatially weighted by $1 /\left[\overline{\tau_{c}}\right]$. The unit of moisture budget terms is $\mathrm{W} \mathrm{m}{ }^{-2}$, therefore the regression coefficient is unitless.

A lag-regression analysis of OLR anomalies and the MJO moisture budget terms revealed that higher moisture recharging before the onset of enhanced convection in the SMC area made MJO propagation smoother in the high-MMG years. The difference in the total moisture tendency between the high-MMG and low-MMG years was mostly contributed by that of meridional advection. Moreover, the results showed that the difference in the meridional moisture advection term was mainly due to the term that was higher with a steeper gradient of mean PW: the advection of the mean moisture by the MJO-perturbed meridional wind. With the greater amount of moisture supply, particularly in the mid- to lower free troposphere, the onset and subsequent development of MJO convection in the SMC were more robust in the highMMG years. On the contrary, with much weaker meridional moisture advection, the MJO convection for MJO maintenance tended to be suppressed in the SMC during the lowMMG years. This condition in the low-MMG years revealed that the "MC barrier effect" (Kim et al. 2014; Jing Feng et al. 2015; Zhang and Ling 2017) was enhanced during the years with a flattened meridional gradient of the mean state moisture in the SMC.

Our results strongly suggest that the mean state moisture has profound impacts on the propagation of the MJO across the $\mathrm{MC}$ region at the interannual time scale, supporting the notion that the background moisture in the vicinity of $\mathrm{MC}$ plays an important role on the MJO (Gonzalez and Jiang 2017; Jiang 2017; Ahn et al. 2020a,b; Kang et al. 2020). In particular, we found that a steeper MMG in the SMC provides a favorable condition for $\mathrm{MJO}$ maintenance and propagation while the $\mathrm{MJO}$ is propagating across the $\mathrm{MC}$ area. It is worthwhile to mention that our analysis was guided by a particular branch of the moisture mode theory for MJO that emphasizes horizontal moisture advection, which has its own limitation (e.g., Kacimi and Khouider 2018). As mentioned earlier, the moisture mode theory is one of many existing theories, and it may be possible to explain the observed year-to-year MJO variability from a viewpoint of other MJO theories. More work needs to be done to fully account for the diverse views on the MJO.

Another area that needs further attention is the differing impacts of extreme and normal El Niño/La Niña events on the mean state moisture distribution in the Indo-Pacific warm pool region. While in this study the extreme El Niño events were excluded because they appear to affect the seasonal mean moisture in the IO more strongly than in the SMC, the mechanism through which El Niño events with different magnitudes have different impacts on the mean state moisture remains elusive. Several previous studies also showed a notable difference in seasonal MJO activity between years of the two types of El Niño, with the MJO being weaker during EP El Niño events and being stronger during CP El Niño events (Chen et al. 2016; Hsu and Xiao 2017; Wang et al. 2018; Wei and Ren 2019). Better understanding how El Niño modulates the mean state moisture might shed new light on the underlying mechanism of the difference in MJO characteristics between EP and CP El Niño years.

Including this study, there is a growing body of evidence that underscores the role of the mean state moisture gradient in the dynamics of the MJO. The results of a few recent studies that analyzed hindcast datasets strongly suggest that the mean state moisture bias is a factor that affects MJO forecast skill in dynamical model predictions. The forecast models tend to underestimate moisture advection associated with the MJO, mainly due to a systematic dry bias in the mean state moisture (Kim 2017; Kim et al. 2019). Furthermore, the forecast models that simulate a steeper horizontal gradient of mean moisture tend to exhibit a higher MJO forecast skill (Kim 2017; Lim et al. 2018; Kim et al. 2019). Improving the bias in the mean state moisture might help enhance MJO forecast skill in the models. The question of what determines the mean state MMG, however, remains elusive. Further studies are warranted to better understand the factors that influence the basic state moisture distribution over the Indo-Pacific warm pool region, especially in 
a) Meridional adv. (dashed: T4)

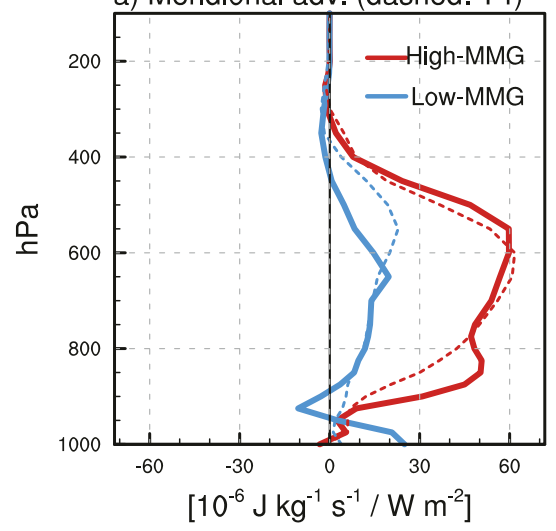

b) Bandpass-filtered v

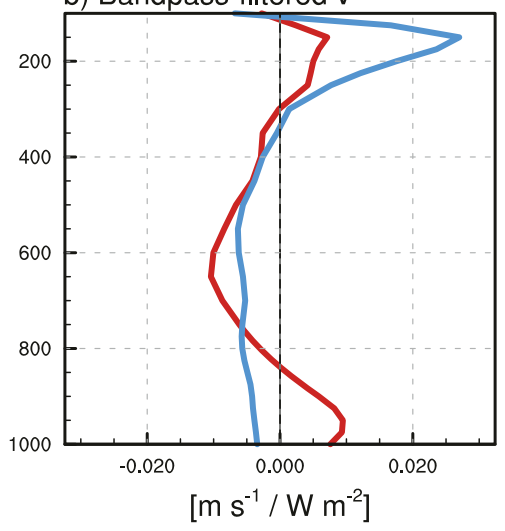

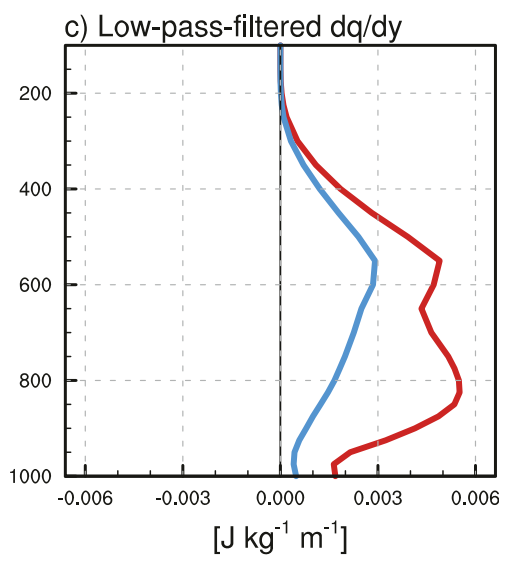

FIG. 12. (a) Vertical profile of meridional moisture advection in the SMC $\left(12.5^{\circ}-5^{\circ} \mathrm{S}, 90^{\circ}-150^{\circ} \mathrm{E}\right.$; the red box in Fig. 10$)$ averaged over lag days from -2 to 2 in the high-MMG years (red) and the low-MMG years (blue). Data were obtained from lagged regression of the variables onto the reference time series of bandpass-filtered $\operatorname{OLR}\left(\mathrm{W} \mathrm{m}^{-2}\right)$ averaged in the IO base point $\left(5^{\circ} \mathrm{S}-5^{\circ} \mathrm{N}, 75^{\circ}-85^{\circ} \mathrm{E}\right)$. Solid and dashed lines indicate the total meridional moisture advection and that by T4, respectively. (b) As in (a), but for 20-100-day bandpassfiltered meridional wind. (c) Vertical profile of the mean state (100-day low-pass filtered) meridional moisture gradient during the highMMG years (red) and the low-MMG years (blue).

the vicinity of the MC, in observations as well as in Earth system models.

Acknowledgments. We thank the anonymous reviewers for their constructive comments on an earlier version of the manuscript. This work was funded by the NOAA CVP program (NA18OAR4310300), DOE RGMA program (DESC0016223), the NASA MAP program (80NSSC17K0227) and KMA R\&D Program (KMI2021-01210). S.-I. An was supported by a National Research Foundation of Korea (NRF) grant funded by the Korean Government (MSIT) (NRF2018R1A5A1024958) and the LG Yonam Foundation of Korea. D. Kang was supported by Sejong Science Fellowship funded by the National Research Foundation of Korea (NRF-2021R1C1C2004621). Work of the LLNL-affiliated author (MSA) was performed under the auspices of the U.S. Department of Energy by Lawrence Livermore National Laboratory under Contract DE-AC52-07NA27344 and their efforts were supported by the Regional and Global Climate Modeling Program of the United States Department of Energy's Office of Science.

\section{REFERENCES}

Adames, Á. F., 2017: Precipitation budget of the Madden-Julian oscillation. J. Atmos. Sci., 74, 1799-1817, https://doi.org/ 10.1175/JAS-D-16-0242.1.

_ , and J. M. Wallace, 2014: Three-dimensional structure and evolution of the vertical velocity and divergence fields in the MJO. J. Atmos. Sci., 71, 4661-4681, https://doi.org/10.1175/JASD-14-0091.1.

— , and D. Kim, 2016: The MJO as a dispersive, convectively coupled moisture wave: Theory and observations. J. Atmos. Sci., 73, 913-941, https://doi.org/10.1175/JAS-D-15-0170.1.

, _ _ E. D. Maloney, and A. H. Sobel, 2020: The moisture mode framework of the Madden-Julian oscillation. The Multiscale Global Monsoon System, C. P. Chang et al., Eds., World Scientific Series on Asia-Pacific Weather and Climate,
Vol. 11, World Scientific, 273-287, https://doi.org/10.1142/ 11723.

Ahn, M.-S., D. Kim, Y.-G. Ham, and S. Park, 2020a: Role of Maritime Continent land convection on the mean state and MJO propagation. J. Climate, 33, 1659-1675, https://doi.org/ 10.1175/JCLI-D-19-0342.1.

,- — - D. Kang, J. Lee, K. R. Sperber, P. J. Gleckler, X. Jiang, Y.-G. Ham, and H. Kim, 2020b: MJO propagation across the Maritime Continent: Are CMIP6 models better than CMIP5 models? Geophys. Res. Lett., 47, e2020GL087250. https:// doi.org/10.1029/2020GL087250.

Andersen, J. A., and Z. Kuang, 2012: Moist static energy budget of MJO-like disturbances in the atmosphere of a zonally symmetric aquaplanet. J. Climate, 25, 2782-2804, https://doi.org/ 10.1175/JCLI-D-11-00168.1.

Ashok, K., S. K. Behera, S. A. Rao, H. Weng, and T. Yamagata, 2007: El Niño Modoki and its possible teleconnection. J. Geophys. Res., 112, C11007, https://doi.org/10.1029/2006JC003798.

Azzalini, A., and A. Capitanio, 1999: Statistical applications of the multivariate skew normal distribution. J. Roy. Stat. Soc., 61B, 579-602, https://doi.org/10.1111/1467-9868.00194.

Benedict, J. J., M. S. Pritchard, and W. D. Collins, 2015: Sensitivity of MJO propagation to a robust positive Indian Ocean dipole event in the superparameterized CAM. J. Adv. Model. Earth Syst., 7, 1901-1917, https://doi.org/10.1002/2015MS000530.

Bessafi, M., and M. C. Wheeler, 2006: Modulation of South Indian Ocean tropical cyclones by the Madden-Julian oscillation and convectively coupled equatorial waves. Mon. Wea. Rev., 134, 638-656, https://doi.org/10.1175/MWR3087.1.

Bond, N. A., and G. A. Vecchi, 2003: The influence of the MaddenJulian oscillation on precipitation in Oregon and Washington. Wea. Forecasting., 18, 600-613, https://doi.org/10.1175/15200434(2003)018<0600:TIOTMO > 2.0.CO;2.

Bretherton, C. S., M. E. Peters, and L. E. Back, 2004: Relationships between water vapor path and precipitation over the tropical oceans. J. Climate, 17, 1517-1528, https://doi.org/10.1175/15200442(2004)017<1517:RBWVPA>2.0.CO;2.

Camargo, S. J., M. C. Wheeler, and A. H. Sobel, 2009: Diagnosis of the MJO modulation of tropical cyclogenesis using an 
empirical index. J. Atmos. Sci., 66, 3061-3074, https:// doi.org/10.1175/2009JAS3101.1.

Cassou, C., 2008: Intraseasonal interaction between the MaddenJulian oscillation and the North Atlantic oscillation. Nature, 455, 523-527, https://doi.org/10.1038/nature07286.

Chen, X., J. Ling, and C. Li, 2016: Evolution of the Madden-Julian oscillation in two types of El Niño. J. Climate, 29, 1919-1934, https://doi.org/10.1175/JCLI-D-15-0486.1.

Chikira, M., 2014: Eastward-propagating intraseasonal oscillation represented by Chikira-Sugiyama cumulus parameterization. Part II: Understanding moisture variation under weak temperature gradient balance. J. Atmos. Sci., 71, 615-639, https:// doi.org/10.1175/JAS-D-13-038.1.

DeMott, C. A., B. O. Wolding, E. D. Maloney, and D. A. Randall, 2018: Atmospheric mechanisms for MJO decay over the Maritime Continent. J. Geophys. Res. Atmos., 123, 5188-5204, https://doi.org/10.1029/2017JD026979.

—, N. P. Klingaman, W. L. Tseng, M. A. Burt, Y. Gao, and D. A. Randall, 2019: The convection connection: How ocean feedbacks affect tropical mean moisture and MJO propagation. J. Geophys. Res. Atmos., 124, 11 910-11 931, https://doi.org/ 10.1029/2019JD031015.

Dole, R., and Coauthors, 2013: The making of an extreme event: Putting the pieces together. Bull. Amer. Meteor. Soc., 95, 427440, https://doi.org/10.1175/BAMS-D-12-00069.1.

Feng, Jing, T. Li, and W. Zhu, 2015: Propagating and nonpropagating MJO events over the Maritime Continent. J. Climate, 28, 84308449, https://doi.org/10.1175/JCLI-D-15-0085.1.

Feng, Juan, P. Liu, W. Chen, and X. Wang, 2015: Contrasting Madden-Julian oscillation activity during various stages of EP and CP El Niños. Atmos. Sci. Lett., 16, 32-37, https:// doi.org/10.1002/asl2.516.

Feng, M., C. Böning, A. Biastoch, E. Behrens, E. Weller, and Y. Masumoto, 2011: The reversal of the multi-decadal trends of the equatorial Pacific easterly winds, and the Indonesian Throughflow and Leeuwin Current transports. Geophys. Res. Lett., 38, L11604, https://doi.org/10.1029/2011GL047291.

— M. J. McPhaden, S.-P. Xie, and J. Hafner, 2013: La Niña forces unprecedented Leeuwin Current warming in 2011. Sci. Rep., 3 (1), 1-9, https://doi.org/10.1038/srep01277.

—, H. H. Hendon, S.-P. Xie, A. G. Marshall, A. Schiller, Y. Kosaka, N. Caputi, and A. Pearce, 2015: Decadal increase in Ningaloo Niño since the late 1990s. Geophys. Res. Lett., 42, 104-112, https://doi.org/10.1002/2014GL062509.

Fuchs, Ž., and D. J. Raymond, 2017: A simple model of intraseasonal oscillations. J. Adv. Model. Earth Syst., 9, 1195-1211, https://doi.org/10.1002/2017MS000963.

Gonzalez, A. O., and X. Jiang, 2017: Winter mean lower tropospheric moisture over the Maritime Continent as a climate model diagnostic metric for the propagation of the MaddenJulian oscillation. Geophys. Res. Lett., 44, 2588-2596, https:// doi.org/10.1002/2016GL072430.

Gualdi, S., A. Navarra, and G. Tinarelli, 1999: The interannual variability of the Madden-Julian oscillation in an ensemble of GCM simulations. Climate Dyn., 15, 643-658, https://doi.org/ 10.1007/s003820050307.

Gushchina, D., and B. Dewitte, 2012: Intraseasonal tropical atmospheric variability associated with the two flavors of El Niño. Mon. Wea. Rev., 140, 3669-3681, https://doi.org/10.1175/ MWR-D-11-00267.1.

Henderson, G., B. Barrett, and D. M. Lafleur, 2014: Arctic sea ice and the Madden-Julian oscillation (MJO). Climate Dyn., 43, 2185-2196, https://doi.org/10.1007/s00382-013-2043-y.
Hendon, H. H., and S. Abhik, 2018: Differences in vertical structure of the Madden-Julian oscillation associated with the quasi-biennial oscillation. Geophys. Res. Lett., 45, 4419-4428, https://doi.org/10.1029/2018GL077207.

_ C. Chang, and J. D. Glick, 1999: Interannual variation of the Madden-Julian oscillation during austral summer. J. Climate, 12, 2538-2550, https://doi.org/10.1175/1520-0442(1999)012<2538: IVOTMJ $>2.0 . \mathrm{CO} ; 2$.

—, M. C. Wheeler, and C. Zhang, 2007: Seasonal dependence of the MJO-ENSO relationship. J. Climate, 20, 531-543, https:// doi.org/10.1175/JCLI4003.1.

Hersbach, H., and Coauthors, 2019: Global reanalysis: Goodbye ERA-Interim, hello ERA5. ECMWF Newsletter, No. 159, ECMWF, Reading, United Kingdom, 17-24, https://doi.org/ 10.21957/vf291hehd7.

Hsu, P.-C. C., and T. Xiao, 2017: Differences in the initiation and development of the Madden-Julian oscillation over the Indian Ocean associated with two types of El Niño. J. Climate, 30, 1397-1415, https://doi.org/10.1175/JCLI-D16-0336.1.

Huffman, G. J., and Coauthors, 2007: The TRMM Multisatellite Precipitation Analysis (TMPA): Quasi-global, multiyear, combinedsensor precipitation estimates at fine scales. J. Hydrometeor., 8, 38-55, https://doi.org/10.1175/JHM560.1.

Jiang, X., 2017: Key processes for the eastward propagation of the Madden-Julian oscillation based on multimodel simulations. J. Geophys. Res., 122, 755-770, https://doi.org/ 10.1002/2016JD025955.

— , Á. F. Adames, M. Zhao, D. Waliser, and E. Maloney, 2018: A unified moisture mode framework for seasonality of the Madden-Julian oscillation. J. Climate, 31, 4215-4224, https:// doi.org/10.1175/JCLI-D-17-0671.1.

— , and Coauthors, 2020: Fifty years of research on the MaddenJulian oscillation: Recent progress, challenges, and perspectives. J. Geophys. Res. Atmos., 125, e2019JD030911, https:// doi.org/10.1029/2019JD030911.

Jones, C., 2000: Occurrence of extreme precipitation events in California and relationships with the Madden-Julian oscillation. J. Climate, 13, 3576-3587, https://doi.org/10.1175/15200442(2000)013<3576:OOEPEI>2.0.CO;2.

Kacimi, A., and B. Khouider, 2018: The transient response to an equatorial heat source and its convergence to steady state: Implications for MJO theory. Climate Dyn., 50, 3315-3330, https://doi.org/10.1007/s00382-017-3807-6.

Kang, D., D. Kim, M.-S. Ahn, R. Neale, J. Lee, and P. Glecker, 2020: The role of the mean state on MJO simulation in CESM2 ensemble simulation. Geophys. Res. Lett., 47, e2020GL089824, https://doi.org/10.1029/2020GL089824.

Kao, H. Y., and J. Y. Yu, 2009: Contrasting eastern-Pacific and central-Pacific types of ENSO. J. Climate, 22, 615-632, https:// doi.org/10.1175/2008JCLI2309.1.

Kessler, W. S., 2001: EOF representations of the Madden-Julian oscillation and its connection with ENSO. J. Climate, 14, 3055-3061, https://doi.org/10.1175/1520-0442(2001)014<3055: EROTMJ $>2.0 . \mathrm{CO} ; 2$.

Kiladis, G. N., J. Dias, K. H. Straub, M. C. Wheeler, S. N. Tulich, K. Kikuchi, K. M. Weickmann, and M. J. Ventrice, 2014: A comparison of OLR and circulation-based indices for tracking the MJO. Mon. Wea. Rev., 142, 1697-1715, https://doi.org/ 10.1175/MWR-D-13-00301.1.

Kim, D., J.-S. Kug, and A. H. Sobel, 2014: Propagating versus nonpropagating Madden-Julian oscillation events. J. Climate, 27, 111-125, https://doi.org/10.1175/JCLI-D-13-00084.1. 
- H. Kim, and M. I. Lee, 2017: Why does the MJO detour the Maritime Continent during austral summer? Geophys. Res. Lett., 44, 2579-2587, https://doi.org/10.1002/2017GL072643.

— E. D. Maloney, and C. Zhang, 2020: Review: MJO propagation over the Maritime Continent. The Multiscale Global Monsoon System, C. P. Chang et al., Eds., World Scientific Series on Asia-Pacific Weather and Climate, Vol. 11, World Scientific, 261-272, https://doi.org/10.1142/11723.

Kim, H.-M., 2017: The impact of the mean moisture bias on the key physics of MJO propagation in the ECMWF reforecast. J. Geophys. Res., 122, 7772-7784, https://doi.org/10.1002/ 2017JD027005.

— , M. A. Janiga, and K. Pegion, 2019: MJO propagation processes and mean biases in the SubX and S2S reforecasts. J. Geophys. Res., 124, 9314-9331, https://doi.org/10.1029/2019JD031139.

_ J. M. Caron, J. H. Richter, and I. R. Simpson, 2020: The lack of QBO-MJO connection in CMIP6 models. Geophys. Res. Lett., 47, e2020GL087295, https://doi.org/10.1029/2020GL087295.

Kiranmayi, L., and E. D. Maloney, 2011: Intraseasonal moist static energy budget in reanalysis data. J. Geophys. Res., 116, D21117, https://doi.org/10.1029/2011JD016031.

Klotzbach, P. J., and E. C. J. Oliver, 2015: Modulation of Atlantic Basin tropical cyclone activity by the Madden-Julian oscillation (MJO) from 1905 to 2011. J. Climate, 28, 204-217, https:// doi.org/10.1175/JCLI-D-14-00509.1.

Kug, J.-S., F.-F. Jin, and S.-I. An, 2009: Two types of El Niño events: Cold tongue El Niño and warm pool El Niño. J. Climate, 22, 1499-1515, https://doi.org/10.1175/2008JCLI2624.1.

Lee, J. C., and N. P. Klingaman, 2018: The effect of the quasibiennial oscillation on the Madden-Julian oscillation in the Met Office Unified Model Global Ocean Mixed Layer configuration. Atmos. Sci. Lett., 19, e816, https://doi.org/10.1002/asl.816.

Lee, Y.-Y., and G.-H. Lim, 2012: Dependency of the North Pacific winter storm tracks on the zonal distribution of MJO convection. J. Geophys. Res., 117, D14101, https://doi.org/10.1029/2011JD016417.

Liebmann, B., and C. A. Smith, 1996: Description of a complete (interpolated) outgoing longwave radiation dataset. Bull. Amer. Meteor. Soc., 77, 1275-1277, https://doi.org/10.1175/ 1520-0477-77.6.1274.

— , H. H. Hendon, and J. D. Glick, 1994: The relationship between tropical cyclones of the western Pacific and Indian Oceans and the Madden-Julian oscillation. J. Meteor. Soc. Japan, 72, 401-412, https://doi.org/10.2151/jmsj1965.72.3_401.

Lim, Y., S. W. Son, and D. Kim, 2018: MJO prediction skill of the subseasonal-to-seasonal prediction models. J. Climate, 31, 4075-4094, https://doi.org/10.1175/JCLI-D-17-0545.1.

Lin, H., G. Brunet, and J. Derome, 2009: An observed connection between the North Atlantic Oscillation and the Madden-Julian oscillation. J. Climate, 22, 364-380, https://doi.org/10.1175/2008JCLI2515.1.

Madden, R. A., and P. R. Julian, 1971: Detection of a 4050 day oscillation in the zonal wind in the tropical Pacific. J. Atmos. Sci., 28, 702-708, https://doi.org/10.1175/15200469(1971)028<0702:DOADOI >2.0.CO;2.

—_, and — 1972: Description of global-scale circulation cells in the tropics with a 40-50 day period. J. Atmos. Sci., 29, 1109-1123, https://doi.org/10.1175/1520-0469(1972)029<1109: DOGSCC $>2.0 . \mathrm{CO} ; 2$.

Maloney, E. D., 2009: The moist static energy budget of a composite tropical intraseasonal oscillation in a climate model. J. Climate, 22, 711-729, https://doi.org/10.1175/2008JCLI2542.1.

_ , and D. L. Hartmann, 2000a: Modulation of hurricane activity in the Gulf of Mexico by the Madden-Julian oscillation. Science, 287, 2002-2004, https://doi.org/10.1126/science.287.5460.2002.
- , and - 2000b: Modulation of eastern North Pacific hurricanes by the Madden-Julian oscillation. J. Climate, 13, 1451-1460, https://doi.org/10.1175/1520-0442(2000)013<1451:MOENPH> 2.0.CO;2.

_, and —_, 2001: The Madden-Julian oscillation, barotropic dynamics, and North Pacific tropical cyclone formation. Part I: Observations. J. Atmos. Sci., 58, 2545-2558, https://doi.org/ 10.1175/1520-0469(2001)058<2545:TMJOBD>2.0.CO;2.

Matthews, A. J., 2004: Atmospheric response to observed intraseasonal tropical sea surface temperature anomalies. Geophys. Res. Lett., 31, L14107, https://doi.org/10.1029/2004GL020474.

Nishimoto, E., and S. Yoden, 2017: Influence of the stratospheric quasi-biennial oscillation on the Madden-Julian oscillation during austral summer. J. Atmos. Sci., 74, 1105-1125, https:// doi.org/10.1175/JAS-D-16-0205.1.

Pohl, B., and A. J. Matthews, 2007: Observed changes in the lifetime and amplitude of the Madden-Julian oscillation associated with interannual ENSO sea surface temperature anomalies. J. Climate, 20, 2659-2674, https://doi.org/10.1175/ JCLI4230.1.

Raymond, D. J., 2001: A new model of the Madden-Julian oscillation. J. Atmos. Sci., 58, 2807-2819, https://doi.org/10.1175/ 1520-0469(2001)058<2807:ANMOTM>2.0.CO;2.

Rayner, N. A., 2003: Global analyses of sea surface temperature, sea ice, and night marine air temperature since the late nineteenth century. J. Geophys. Res., 108, 4407, https://doi.org/ 10.1029/2002JD002670.

Ren, P., D. Kim, M. S. Ahn, D. Kang, and H. L. Ren, 2021: Intercomparison of MJO column moist static energy and water vapor budget among six modern reanalysis products. J. Climate, 34, 2977-3001, https://doi.org/10.1175/JCLI-D-20-0653.1.

Roundy, P. E., and G. N. Kiladis, 2006: Observed relationships between oceanic Kelvin waves and atmospheric forcing. J. Climate, 19, 5253-5272, https://doi.org/10.1175/JCLI3893.1.

_ and J. R. Kravitz, 2009: The association of the evolution of intraseasonal oscillations to ENSO phase. J. Climate, 22, 381395, https://doi.org/10.1175/2008JCLI2389.1.

Rushley, S. S., D. Kim, C. S. Bretherton, and M. S. Ahn, 2018: Reexamining the nonlinear moisture-precipitation relationship over the tropical oceans. Geophys. Res. Lett., 45, 11331140, https://doi.org/10.1002/2017GL076296.

Santoso, A., M. J. McPhaden, and W. Cai, 2017: The defining characteristics of ENSO extremes and the strong 2015/2016 El Niño. Rev. Geophys., 55, 1079-1129, https://doi.org/10.1002/ 2017RG000560.

Seo, K.-H., and S.-W. Son, 2012: The global atmospheric circulation response to tropical diabatic heating associated with the Madden-Julian oscillation during northern winter. J. Atmos. Sci., 69, 79-96, https://doi.org/10.1175/2011JAS3686.1.

Slingo, J., D. Rowell, K. Sperber, and F. Nortley, 1999: On the predictability of the interannual behaviour of the Madden-Julian oscillation and its relationship with El Niño. Quart. J. Roy. Meteor. Soc., 125, 583-609, https://doi.org/10.1256/smsqj.55410.

Sobel, A. H., J. Nilsson, and L. M. Polvani, 2001: The weak temperature gradient approximation and balanced tropical moisture waves. J. Atmos. Sci., 58, 3650-3665, https://doi.org/10.1175/ 1520-0469(2001)058<3650:TWTGAA >2.0.CO;2.

_ , and E. Maloney, 2012: An idealized semi-empirical framework for modeling the Madden-Julian oscillation. J. Atmos. Sci., 69, 1691-1705, https://doi.org/10.1175/JAS-D-11-0118.1.

_, and _ 2013: Moisture modes and the eastward propagation of the MJO. J. Atmos. Sci., 70, 187-192, https://doi.org/ 10.1175/JAS-D-12-0189.1. 
— ——, G. Bellon, and D. M. Frierson, 2010: Surface fluxes and tropical intraseasonal variability: A reassessment. J. Adv. Model. Earth Syst., 2, 27, https://doi.org/10.3894/ JAMES.2010.2.2.

Son, S. W., Y. Lim, C. Yoo, H. H. Hendon, and J. Kim, 2017: Stratospheric control of the Madden-Julian oscillation. J. Climate, 30, 1909-1922, https://doi.org/10.1175/JCLID-16-0620.1.

Takayabu, Y. N., T. Iguchi, M. Kachi, A. Shibata, and H. Kanzawa, 1999: Abrupt termination of the 1997-98 El Nino in response to a Madden-Julian oscillation. Nature, 402, 279-282, https:// doi.org/10.1038/46254.

Tam, C. Y., and N. C. Lau, 2005: Modulation of the Madden-Julian Oscillation by ENSO: Inferences from observations and GCM simulations. J. Meteor. Soc. Japan, 83, 727-743, https://doi.org/ 10.2151/jmsj.83.727.

Tang, Y., and B. Yu, 2008: MJO and its relationship to ENSO. J. Geophys. Res., 113, D14106, https://doi.org/10.1029/ 2007JD009230.

Waliser, D. E., Z. Zhang, K. M. Lau, and J.-H. Kim, 2002: Interannual sea surface temperature variability and the predictability of tropical intraseasonal variability. J. Atmos. Sci., 58, 2596-2615, https://doi.org/10.1175/1520-0469(2001) 058<2596:ISSTVA $>2.0$.CO;2.

Wang, B., and H. Rui, 1990: Synoptic climatology of transient tropical intraseasonal convection anomalies: 1975-1985. Meteor. Atmos. Phys., 44, 43-61, https://doi.org/10.1007/BF01026810.

Wang, L., T. Li, E. Maloney, and B. Wang, 2017: Fundamental causes of propagating and nonpropagating MJOs in MJOTF/ GASS models. J. Climate, 30, 3743-3769, https://doi.org/ 10.1175/JCLI-D-16-0765.1.

- - L. Chen, S. K. Behera, and T. Nasuno, 2018: Modulation of the MJO intensity over the equatorial western Pacific by two types of El Niño. Climate Dyn., 51, 687-700, https://doi.org/10.1007/s00382-017-3949-6.

Wang, X., and C. Wang, 2014: Different impacts of various El Niño events on the Indian Ocean dipole. Climate Dyn., 42, 9911005, https://doi.org/10.1007/s00382-013-1711-2.
Wei, Y., and H.-L. Ren, 2019: Modulation of ENSO on fast and slow MJO modes during boreal winter. J. Climate, 32, 74837506, https://doi.org/10.1175/JCLI-D-19-0013.1.

Wheeler, M. C., and H. H. Hendon, 2004: An all-season real-time multivariate MJO index: Development of an index for monitoring and prediction. Mon. Wea. Rev., 132, 1917-1932, https://doi.org/ 10.1175/1520-0493(2004)132<1917:AARMMI>2.0.CO;2.

_ Intraseasonal Variability in the Atmosphere-Ocean Climate System, Springer, 125-173.

Wilson, E. A., A. L. Gordon, and D. Kim, 2013: Observations of the Madden Julian oscillation during Indian Ocean dipole events. J. Geophys. Res. Atmos., 118, 2588-2599, https://doi.org/ 10.1002/jgrd.50241.

Yasunari, T., 1979: Cloudiness fluctuations associated with the Northern Hemisphere summer monsoon. J. Meteor. Soc. Japan, 57, 227-242, https://doi.org/10.2151/jmsj1965.57.3_227.

Yoo, C., and S. W. Son, 2016: Modulation of the boreal wintertime Madden-Julian oscillation by the stratospheric quasi-biennial oscillation. Geophys. Res. Lett., 43, 1392-1398, https://doi.org/ 10.1002/2016GL067762.

Zhang, C., and J. Ling, 2017: Barrier effect of the Indo-Pacific Maritime Continent on the MJO: Perspectives from tracking MJO precipitation. J. Climate, 30, 3439-3459, https://doi.org/ 10.1175/JCLI-D-16-0614.1.

—, and B. Zhang, 2018: QBO-MJO connection. J. Geophys. Res., 123, 2957-2967, https://doi.org/10.1002/2017JD028171.

—, J. Gottschalck, E. D. Maloney, M. W. Moncrieff, F. Vitart, D. E. Waliser, B. Wang, and M. C. Wheeler, 2013: Cracking the MJO nut. Geophys. Res. Lett., 40, 1223-1230, https:// doi.org/10.1002/grl.50244.

— , Á. F. Adames, B. Khouider, B. Wang, and D. Yang, 2020: Four theories of the Madden-Julian oscillation. Rev. Geophys., 58, e2019RG000685, https://doi.org/10.1029/2019RG000685.

Zhang, L., and W. Han, 2020: Barrier for the eastward propagation of Madden-Julian oscillation over the Maritime Continent: A possible new mechanism. Geophys. Res. Lett., 47, e2020GL090211, https://doi.org/10.1029/2020GL090211. 